\title{
Integrated semi-transparent Cadmium Telluride photovoltaic glazing into windows: energy and daylight performance for different architecture designs
}

\author{
Yanyi Sun ${ }^{a^{*}}$, Katie Shanks ${ }^{\mathrm{b}}$, Hasan Baig, Wei Zhang ${ }^{\mathrm{c}}$, Xia Hao ${ }^{\mathrm{c}}$, Yongxue $\mathrm{Li}^{\mathrm{c}}$, Bo He $\mathrm{He}^{\mathrm{c}}$, Robin Wilson ${ }^{\mathrm{a}}$, Hao \\ Liu $^{\mathrm{a}}$, Senthilarasu Sundaram ${ }^{\mathrm{b}}$, Jingquan Zhang ${ }^{\mathrm{c}}$, Lingzhi Xie ${ }^{\mathrm{c}}$, Tapas Mallick ${ }^{\mathrm{b}}$ and Yupeng $\mathrm{Wu}^{\mathrm{a}^{*}}$ \\ ${ }^{a}$ Department of Architecture and Built Environment, The University of Nottingham, University Park, \\ Nottingham, NG7 2RD, UK \\ ${ }^{b}$ Environmental and Sustainability Institute, University of Exeter Penryn Campus, Penryn, TR10 9FE, UK \\ 'Institute of New Energy and Low-carbon Technology, Sichuan University, Chengdu, 610065, PR \\ *Corresponding author: Tel.: +44 11574 84011; fax: +44 11595 13159; \\ Emails: Yanyi.Sun@nottingham.ac.uk (Yanyi Sun); Yupeng.Wu@nottingham.ac.uk (Yupeng Wu)
}

\begin{abstract}
When integrating photovoltaics into building windows, the photovoltaic glazing modules inhibit the function that glass performs, with the additional function of energy production. Semi-transparent Photovoltaic (STPV) glazing will absorb part of the solar radiation incident on the window surface to generate electrical power. In turn, this affects the overall solar energy and natural daylight penetrating the indoor space. Various factors determine the building energy performance and indoor comfort level as a result of adopting STPV glazing. The factors regarding window design alone (window size, PV glazing coverage ratio and PV glazing placing position) require rigorous study. In this paper, an innovate model (combined optical, electrical and energy model) was developed to comprehensively evaluate the performance of an office equipped with STPV window and firstly analyse the effect of window design on overall energy efficiency. A double-glazing unit integrated with thin film CdTe solar cells with $10 \%$ transparency was electrically characterised by Sandia Array Performance Model (SAPM). The annual energy performance of a typical office served by window integrated STPV glazing was investigated through EnergyPlus simulation for various window designs under five typical climatic conditions in China (using weather files of Harbin, Beijing, Shanghai, Guangzhou and Kunming for representation). The optical performance (defined by a Bidirectional Scattering Distribution Function) of this STPV glazing was also obtained using a ray-tracing technique. Then, the annual daylight performance of the porotype office was assessed using RADIANCE. We found that when compared to a conventional double-glazed system, the application of PV window can result in considerable energy saving if the office has a relatively large window-to-wall ratio (i.e. $\geq 45 \%$ ), while the position of placing STPV glazing has significant influence on the lighting energy consumption. In the specific climates under test, the optimal design scenario of applying window integrated PV can result in a reduction in energy consumption of up to $73 \%$. The simulation results also show that this PV window offers better daylight performance than conventional double glazing and effectively reduces the possibility of glare.
\end{abstract}

\section{Keywords:}

Semi-transparent photovoltaic (STPV) glazing; Building Simulation; EnergyPlus; RADIANCE. 


\section{Introduction}

Building-integrated photovoltaic (BIPV) is a concept of integrating photovoltaic elements into the building envelope, establishing a relationship between the architectural design, structure and multi-functional properties of building materials and renewable energy generation [1]. For glazing application, photovoltaic modules replace conventional glass, taking over the function that glass performs, such as weather proofing, thermal control and sound protection, while also including the additional function of on-site electricity production. Although this idea is not a new concept, it has not been widely adopted due to the challenges of extensive planning, relative high cost as well as the challenges of optimizing their performance that affected by environmental variables.

For window and glazing façade PV application, prototypes have been made by crystalline silicon solar cells (e.g. Mono-crystalline(mono c-si), Poly-crystalline (poly c-si)), thin film solar cells (e.g. Amorphous Silicon (a-si), Multi-junction thin film silicon (a-Si/ $\mu c-S i)$, Cadmium telluride (CdTe), Copper-IndiumDiselenide (CIS), Copper-Indium-Dieseline (CIGS)), organic solar cells (e.g. Organic PV (OPV) and Dyesensitized solar cells (DSSC)) [2] as shown in Fig. 1. Crystalline silicon solar cells have the highest cell and module efficiency out of these, but they are opaque, which means the light transmission through the modules can be achieved only by altering the spacing between the cells. Windows and glazing façades integrated with thin-film solar cells and organic solar cells can achieve a uniform appearance and semi-transmittance for daylight without cast shadow inside the room. This provides a better architectural acceptance when compared with crystalline silicon-based STPV facades/ windows [3], [4], [5]. Thin film modules, such as CdTe, consist of thin liner cells of only a few micrometres thickness. Despite the cell efficiency of thin film cells increasing dramatically in only a short number of years ( (e.g. the highest reported cell efficiency for CdTe is $22.1 \%$ [6]), the overall module efficiencies for semi-transparent PV windows are reported in a range of only $4.1 \%-12 \%$ [9] [10], [11], [12], [13], [14]. This is due to the requirement of attaining a certain degree of transparency [7] and the inclusion of cover glass [8] for the integrated thin film window versions of the technology. A new generation of photovoltaic- Organic PV, which has emerged on the market in recent years, is more economic and flexible but with lower electrical efficiency (e.g. module efficiencies for DSSC devices are in the range of $3 \%-7.6 \%$ ) [7], [15]. The long-term durability is however the more serious issue that obstructs their commercial usage [7]. 


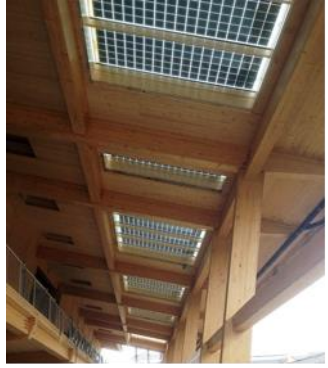

(a) $\mathrm{c}-\mathrm{Si}$

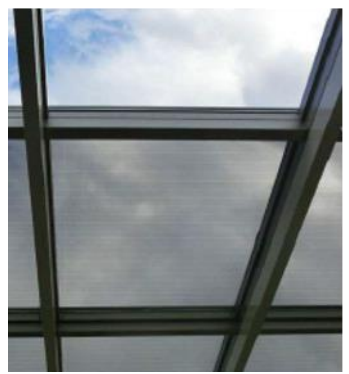

(d) $\mathrm{CdTe}$

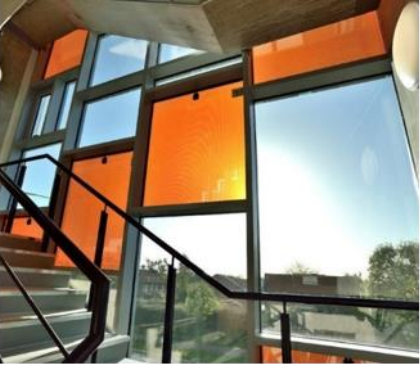

(b) a-Si

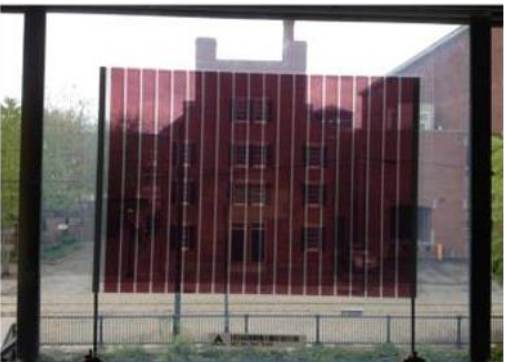

(e) OPV

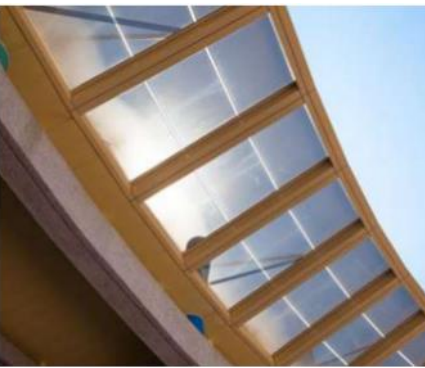

(c) $\mathrm{a}-\mathrm{Si} / \mu \mathrm{c}-\mathrm{Si}$

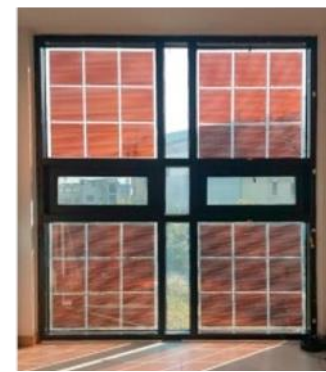

(f) DSSC

Fig. 1: Window integrated with different types of PV cell materials. Sources: [16] [17] [18]

When integrating different types of PV modules into a building window or glazing façade, the variation of thermo-optical (e.g. emissivity, solar and visible) transmittance of the glazing material will affect the fraction of absorbed, transmitted and re-radiated solar radiation, as well as the amount of penetrating daylight. This will in turn affect the temperature of the PV module and thus influence their electrical power generation. The interaction between the thermal, optical and electrical performance of a PV window would eventually affect the indoor environment and the overall building energy consumption. To improve the thermo-optical features of window integrated PV systems, some advanced glazing technologies (e.g. vacuum glazing [19], [20] and compound parabolic concentrator (CPC) [21]) have been seen added into PV windows to improve their overall performance. With the help of building simulation tools, a number of previous simulation studies sought to explore the coupled electrical, thermal, daylight and energy performance of applying solar cells into windows [22]. Peng et al [3], [12], [23], [24] used EnergyPlus to investigate the integrated thermal, power, and daylighting performances of applying a semi-transparent amorphous silicon PV module under the climate of Hong Kong. Pre-simulation measurements of optical characteristics, heat conductivity and infrared emissivity of the PV module, as well as the coefficients for Sandia Array Performance Model (SAPM) were used for optically, thermally and electrically characterising these PV modules when modelling. To validate the EnergyPlus model, outdoor experimental measurements in terms of surface temperature, daylight illuminance, heat gains and hourly power generation have been conducted and these results were compared with that obtained from EnergyPlus simulations under nearly the same physical environment. The measurement results match well with the simulation results with differences less than $4 \%$.

Other than the thermo-optical properties of STPV glazing, the architectural design of a window in a building envelope can also dramatically affect the energy efficiency of the building. Generally, windows are 
the pathway for an indoor space to receive daylight and passive solar radiation, as well as providing, outdoor views. Replacing the clear glazing of a window with STPV glazing will undoubtedly provide on-site solar electricity generation. It will however also result in: a reduction of passive solar heat gain; an increase of lighting energy consumption; and an obstruction of the occupants' view. The balance between the generated electricity and the variation of heating, cooling and lighting energy consumption, which might be increased or decreased, may not always provide positive effects on the overall building energy efficiency. It is highly dependent on the window size (represented by Window-to-Wall Ratio (WWR), which is the ratio of the area of window to the area of wall), solar cells coverage, STPV glazing position and the transmittance of the STPV glazing, as well as the climate conditions that the building located. The influences of WWR and STPV glazing transmittance on the overall energy performance of a building have been investigated by previous researchers. Chow et al [25] used a simple power output equation in conjunction with a 2D heat-transfer model and daylight simulation module in EnergyPlus to investigate the performance of a semi-transparent a-Si window's performance on an office building in Hong Kong. Their results showed that a visible transmittance in the range of $0.45-0.55$ achieves the best energy-saving performance when the WWR is 0.33. Olivieri et al. [26], [27] used a package of specific software tools (DesignBuilder, EnergyPlus, PVsyst, and COMFEN) to investigated the thermal, power and daylighting effects of applying Semi-Transparent PV facades with different transmittances under different window-to-wall ratios. Their results indicate that, a) for small openings (WWR $\leq 33 \%$ ), various transmittances of STPV glazing provide negligible difference on the overall energy efficiency; b) for intermediate openings $(33 \%<\mathrm{WWR}<66 \%)$, STPV glazing with a transmittance of $16 \%$ gives rise to the greatest energy saving potential; and c) for large openings (WWR $\geq 66 \%$ ), STPV glazing with a transmittance of $10 \%$ yield the lowest energy consumption. Miyazaki et al. [22] used EnergyPlus to investigate the effect of the PV window transmittance and window to wall ratio (WWR) on office buildings' heating and cooling loads, daylighting, and electricity production. Their results revealed that a solar cell transmittance of $40 \%$ and WWR of $50 \%$ achieved the minimum electricity consumption under Tokyo's climate. Kapsis [28] investigated the annual daylight performance of various STPV window configurations using DAYSIM under cooling dominated continental climate. The impact of WWR, orientation and lighting design (load density and lighting control) on the selection of ideal optical properties of semi-transparent photovoltaics (poly-Si, a-Si, OPV) was studied. Semi-transparent photovoltaic module with 10\% visible effective transmittance resulted in the lowest annual end-use electricity consumption. Skandalos et al [10] used TRNsys to study the optical and thermal properties, as well as the thermal performance of windows integrated with a-Si and c-Si solar cells under a typical warm Mediterranean climate. Their results show that the adoption of window integrated STPV glazing significantly reduced cooling loads and increased the heating load, while the overall energy efficiency depends on solar cell coverage ratio and the electrical load connection.

However, nearly all of the current studies focused on applying STPV glazing all over the whole window area. There is little in the literature that investigates the performance of different window designs 
combing clear glazing with STPV glazing, which is regarded as a more applicable strategy for designers and occupants. It is considered a more applicable strategy because of the following reasons: 1) combinations of clear glazing and STPV glazing can provide a contrast of colour, variation of texture and an aesthetic pattern; and 2) the sections of clear glazing provide unobstructeds view into and out of a building.

This research assesses, for the first time, the impact of design factors of window integrated semitransparent PV glazing on building energy performance and luminous environment quality when subjected to varying climate conditions. A typical office with varying Window-to-Wall ratio, different PV glazing covering rates and different PV glazing's placing position within the window were modelled and simulated. The modelling approach is distinguished through using Sanida model to represent electrical behaviour and its combination with using BSDF for representing optical performance within existing building energy performance software. The findings will suggest ways in which window integrated STPV glazing might be used in future building applications, providing a criteria for architects, designers and engineers.

In this research, an innovative model (combined optical, electrical and energy model) was developed to comprehensively evaluate performance of an office served by STPV windows. Glazing with integrated thin film CdTe solar cells with $10 \%$ transparency was selected due to its better compatibility with windows and also high electrical conversion efficiency. EnergyPlus (v8.1) and RADIANCE (v5.1) were used for energy and daylight performance simulations to demonstrate how the integrated thin film CdTe window system influences as office environment with different window architecture under five distinctive climates in China. 


\section{Research Methodology}

In this research, commercially available semi-transparent thin film CdTe glazing with $10 \%$ transparency (i.e. $90 \%$ area of the glazing is covered by solar cells) was chosen as the example technology. Different architectural designs of applying the window integrated semi-transparent CdTe PV glazing were then compared for their effect on the daylight and energy performance of the indoor spaces under different climates. EnergyPlus (v 8.1) was used to explore the influence of CdTe glazing on building heating, cooling and lighting energy demand as well as the power generation rate of implementing window integrated PV. The daylight performance predictions in terms of daylight availability and daylight comfort can be performed using annual hourly simulation results obtained from RADIANCE (v 5.1).

\subsection{CdTe window unit}

The commercial semi-transparent thin film CdTe window is shown in Fig. 2 (a). As can be seen, solar cells are spaced evenly to attain daylight penetration and outdoor views. To rigorously characterise its optical properties, a ray-tracing program, genBSDF in RADIANCE was used to generate a Bidirectional Scattering Distribution Function (BSDF) of the CdTe window. This BSDF file defines coefficients to allocate light from each exterior direction (i.e. incident solar radiation) to each interior direction. This calculation is based on accurate definitions of geometry and material properties of the CdTe window. The BSDF file was then input to WINDOW (v7.6) to obtain the CdTe window's thermal properties. The test rig climate chamber in the Energy Technology Building, University of Nottingham has also been used to measure the thermal resistance of this CdTe window under standard conditions and the test results validated the calculated thermal properties. The $\mathrm{U}$-value of the CdTe window is $2.54 \mathrm{~W} / \mathrm{m}^{2} \mathrm{~K}$. The electrical characteristics of the CdTe window used in this study was extracted and calculated from a series of indoor and outdoor tests that were conducted by a third party. Key features at standard test conditions are listed as follows: Voc 90 V, Isc 1A, Vmpp 65 V and Impp 0.77 A. Details of the thermal and electrical tests will be published in separate papers as these are beyond the scopes of this paper.

\subsection{Prototype office geometry and modelling}

A single office room, which is considered as part of a large south-facing façade building, was used in the simulation study. The prototype office has dimensions of $2.9 \mathrm{~m}$ (width) $\times 4.4 \mathrm{~m}($ depth $) \times 3.3 \mathrm{~m}$ (height) as shown in Fig. 2 (b). The floor, ceiling and walls were treated as perfectly diffuse with visible reflectances of $30 \%, 80 \%$ and $80 \%$ respectively. Influences from surrounding buildings, vegetation or other obstructions were ignored in the simulation. The windows under test were assumed to be mounted on the south wall, which is also the only surface of the room that was exposed to external conditions while the other surfaces of the room were assumed to be buffered by mechanically conditioned spaces and therefore experienced no interzonal heat flow. 


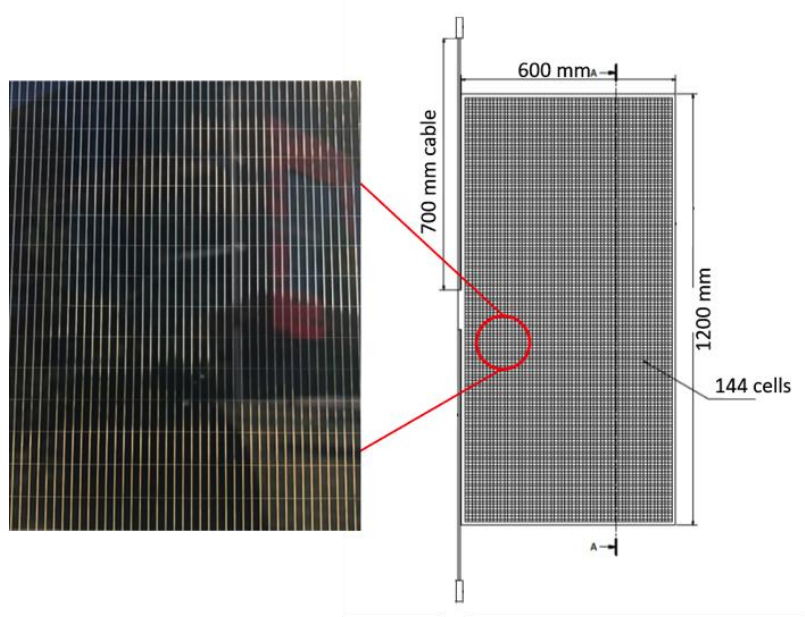

(a)

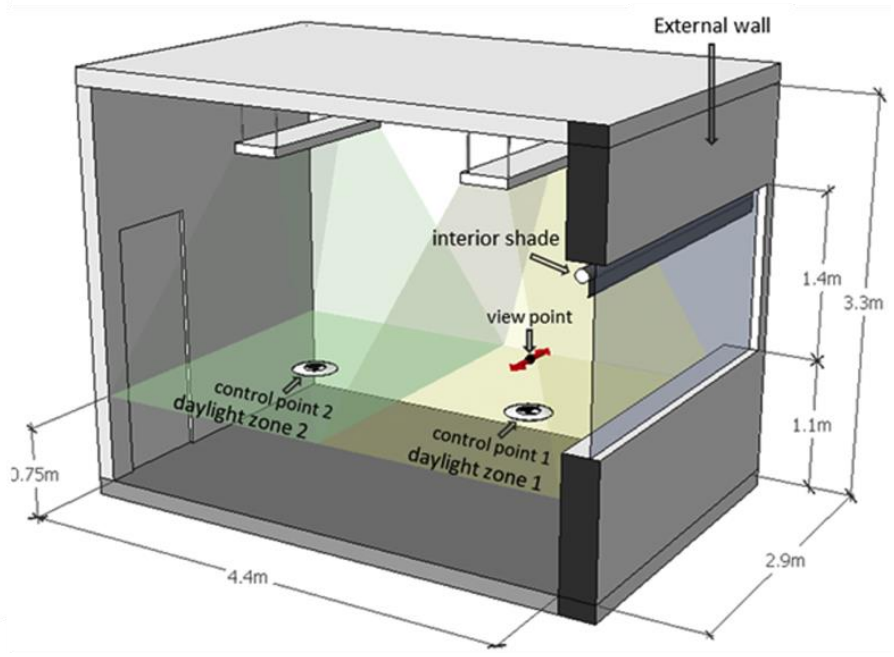

(b)

Fig. 2: (a) CdTe PV window unit and (b) schematic diagram of prototype office

\subsection{Scenarios of façade design}

Window-to-wall ratio is the ratio between the area of window and the area of the whole façade [29], which is an important façade design factor that decides the energy efficient of a building [30]. The rule-ofthumb in architecture design is that a small to middle-sized window-to-wall ratio is regarded as the most energy efficient façade design [31], [32]. For example, the optimal WWR that lead to the lowest energy consumption was found to be $35 \%-45 \%$ under a central Europe representative climate [33]. A larger windowto-wall ratio will maximize the daylight availability and views of adjacent environments, which is becoming increasingly welcome in moderate architecture design. However, due to the low thermal insulation property and the direct transmittance of solar energy and natural daylight of glazing units, a larger glazing area will increase the exposure and sensitivity of the indoor space to the outdoor weather conditions. Hence, this will increase the potential for the indoor space being influenced by, for example, over-illumination, overheating or underheating, the latter two possibly leading to increased energy consumption for $\mathrm{AC}$ or room heating to compensate [34].

STPV glazing will absorb a fraction of the solar radiation incident on thewindow surface (to generate electrical power) and thus obstruct the overall solar energy and natural daylight that would otherwise penetrate the inside space. Enlarging the covering area of STPV glazing will lead to more power generation but consequently result in less available daylight and increased lighting energy consumption. Meanwhile, the presence of PV solar cells on the window glazing will also reduce the transmitted solar heat gain, which may lead to less cooling load in summer and more heating load in winter. Thus, exploring the optimized proportion of STPV glazing under different window-to-wall ratio plays crucial roles in determining the overall net energy consumption.

In this research, four different window-to-wall ratios (WWRs) are considered to represent small, medium, large or extra-large window. In the purpose of exploring to which extent the window surfaces 
covered by STPV glazing can give rise to the lowest energy demands and provide best daylight performance, a variety of STPV glazing covering ratios were considered (bare, $0 \%$ - fully covered, 100\%) under each window-to-wall ratio group. Both normal clear double-glazing pane and STPV glazing pane have a fixed dimension, which is $1200 \mathrm{~mm}$ by $600 \mathrm{~mm}$, to provide modularity variation of façade design scenarios. To investigate the optimum position for placing STPV glazing on a window, different window layout designs for the same covering rate of each window-to-wall ratio are considered. Thus, totally 38 architecture design scenarios were tested in this research as shown in Fig. 3.
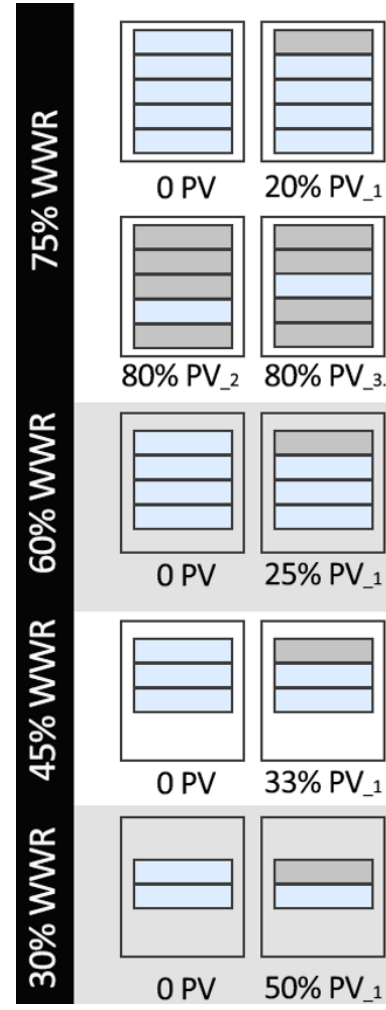

OPV

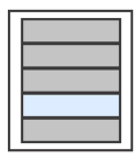

$20 \%$ PV

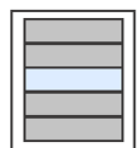

$80 \% \mathrm{PV}_{-} 2$

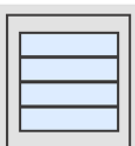

$80 \%$ PV
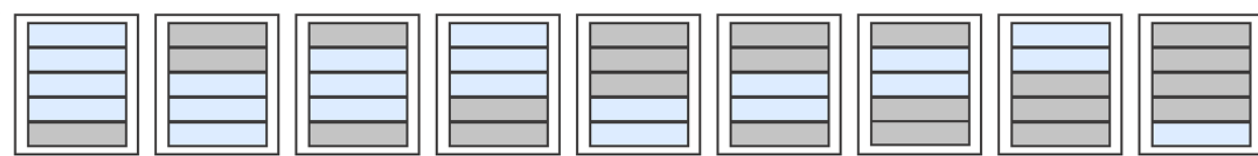

$40 \% \mathrm{PV}_{3} 60 \% \mathrm{PV}$

$60 \% \mathrm{PV}_{2}$

$60 \%$ PV

$60 \% \mathrm{PV}_{-} 480 \% \mathrm{PV}_{-} 1$
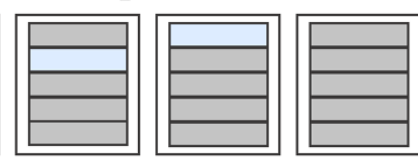

$80 \% \mathrm{PV}_{5} \quad 100 \% \mathrm{PV}$
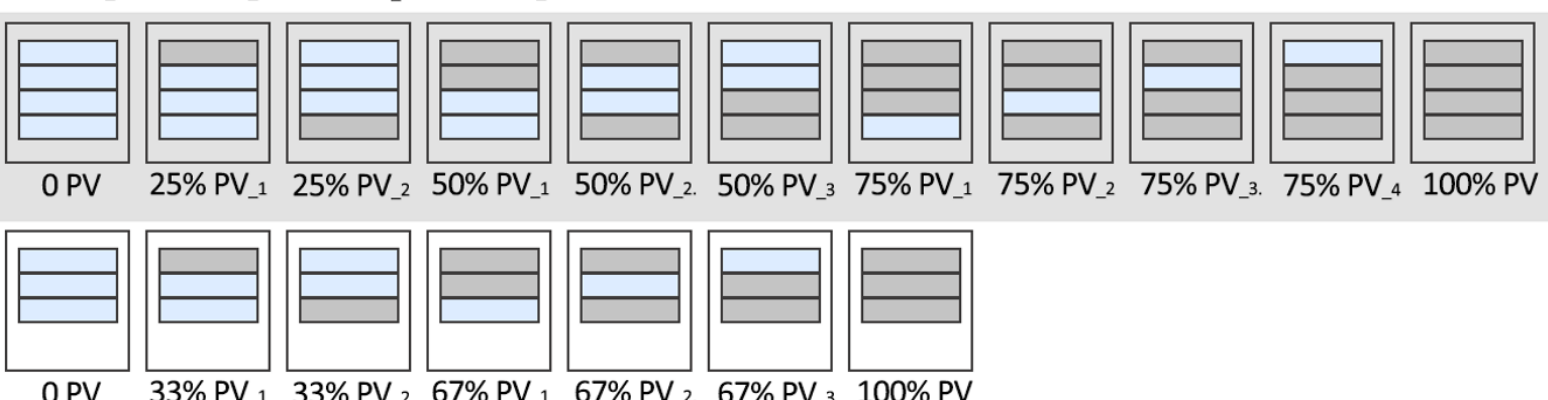

$67 \%$ PV

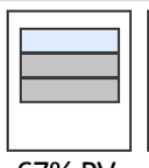

$75 \% \mathrm{PV}_{-} 1$

$75 \% \mathrm{PV}_{2}$

$75 \% P V_{3} .75 \% P V_{4} \quad 100 \%$ PV
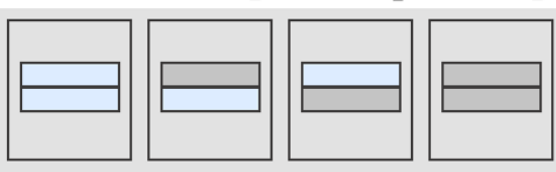

$67 \% \mathrm{PV}_{3} \quad 100 \% \mathrm{PV}$

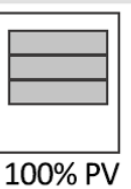

OPV

$50 \% \mathrm{PV}_{-}$

$50 \% \mathrm{PV}_{2} 2 \quad 100 \% \mathrm{PV}$

Fig. 3: Façade design scenarios

\subsection{Weather data in building simulation}

When conducting building related practice and research, the whole country of China can be divided into five climate zones according to their distinct meteorological characteristics (Fig. 4 (a)). In this research, Five cities: Harbin, Beijing, Shanghai, Guangzhou and Kunming (i.e. one in each climate zones) have been selected to represent different climate and solar radiation conditions (Table 1). The building performance simulations were performed in one-hour time steps for an entire year using the IWEC (International Weather for Energy Calculation) weather data of these five cities. 


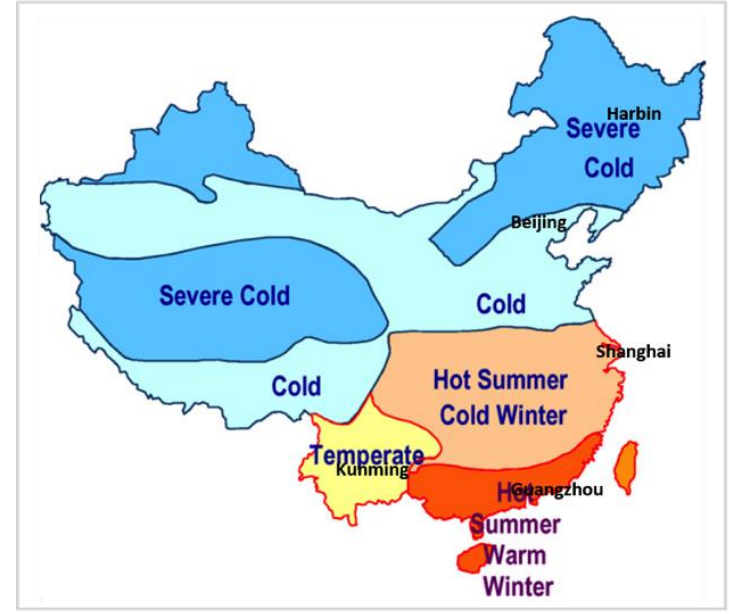

(a)

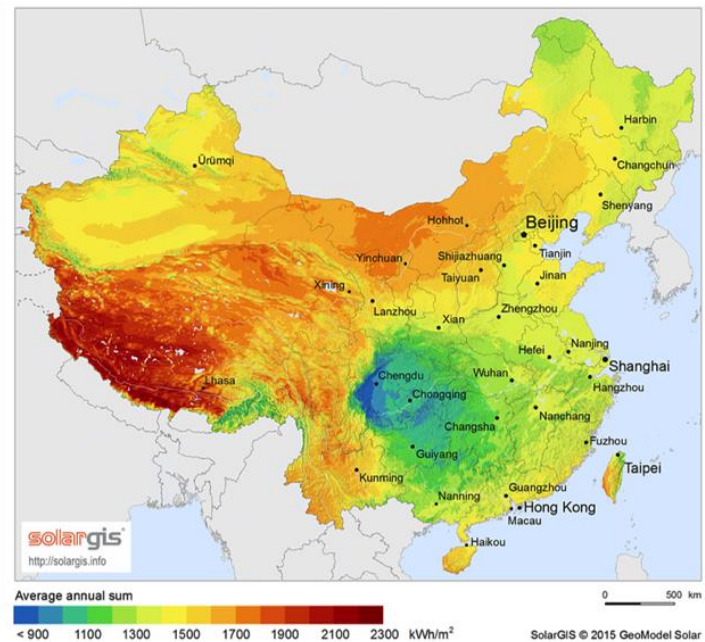

(b)

Fig. 4: (a) China climate zones [35] (b) China global horizontal irradiation map [36]

Table 1: Latitude, longitude, summer and winter average temperatures and solar irradiance of 5 cities

\begin{tabular}{cccccc}
\hline & Latitude & Longitude & $\begin{array}{c}\text { Summer avg. } \\
\text { temp. }\left({ }^{\circ} \mathbf{C}\right)\end{array}$ & $\begin{array}{c}\text { Winter avg. } \\
\text { temp. }\left({ }^{\circ} \mathbf{C}\right)\end{array}$ & $\begin{array}{c}\text { Annual average solar } \\
\text { irradiance }\left(\mathbf{k W h} / \mathbf{m}^{2}\right)\end{array}$ \\
\hline Harbin & $45.7^{\circ} \mathrm{N}$ & $126.7^{\circ} \mathrm{E}$ & 21.5 & -16.5 & $1250-1350$ \\
Beijing & $39.9^{\circ} \mathrm{N}$ & $116^{\circ} \mathrm{E}$ & 25.4 & -1.1 & $1400-1500$ \\
Shanghai & $31.2^{\circ} \mathrm{N}$ & $121.4^{\circ} \mathrm{E}$ & 27 & 5.3 & $1300-1400$ \\
Guangzhou & $23.1^{\circ} \mathrm{N}$ & $113.3^{\circ} \mathrm{E}$ & 28.3 & 14.7 & $1350-1450$ \\
Kunming & $25^{\circ} \mathrm{N}$ & $102.3^{\circ} \mathrm{E}$ & \multicolumn{2}{c}{$8-18$} & $1600-1700$ \\
\hline
\end{tabular}

\subsection{Simulation methods and conditions}

\subsubsection{EnergyPlus settings for energy simulation}

EnergyPlus is a validated and widely accepted simulation tool for exploring a building's thermal, daylight and energy performance [37]. Its capabilities for modelling complex window systems with 2D or 3D thermal or optical entities and its allowance of source code accessment and modification make EnergyPlus a competent software for this research.

The Sandia Array Performance Model (SAPM), which uses empirically determined coefficients of a PV panel to predict its electrical performance, was used to electrically characterise the window integrated semi-transparent CdTe PV glazing. SAPM is tightly coupled to the surface heat balance and uses the result of surface temperature as the solar cell's operating temperature [3]. Using SAPM to characterise semi-transparent thin film PV module in building performance simulation has been validated by Peng et al [23]. The BSDF file that was derived from a ray-tracing technique was also input to EnergyPlus (bridged by WINDOW) for optically characterising the CdTe window system. The loads for equipment and lighting were assumed to be 
$13 \mathrm{~W} / \mathrm{m}^{2}$ and $16 \mathrm{~W} / \mathrm{m}^{2}$ to represent normal office electric appliance and typical fluorescent lighting, respectively. The thermostat action-points were hence $21^{\circ} \mathrm{C}$ for heating and $25^{\circ} \mathrm{C}$ for cooling.

The room is assumed to be used as a private office for two people from 8:00 to 17:00 on weekdays, with one position near the window and the second at the back of the room. Thus, as shown in Fig. 2, the room was divided into two daylighting zones with two control sensors located at the centre of each daylighting zone at a height of $0.75 \mathrm{~m}$ (representing the height of the working place). An illuminance level threshold of $500 \mathrm{~lx}$ at each sensor, which is the lower limit for task lighting [38], was used to determine the switching profile of the lighting system with the appropriate sensor individually controlling its own luminaire.

\subsubsection{RADIANCE settings for daylight simulation}

RAIDANCE is a software tool based on a backward ray-tracing algorithm [39]. The accuracy of this research grade simulation tool has been validated by several studies [40], [41], [42], [43]. 'Three-phase method' [44], [45], which represents flux transfer using corresponding matrices between daylight, fenestration system and points of interest, was used to conduct the dynamic annual daylight simulation of applying window integrated CdTe glazing in the office. The daylight matrix and view matrix were obtained based on the orientation, surrounding environment, geometry and surface properties of the modelled office in RADIANCE. The transmission matrix for window integrated CdTe glazing was expressed using BSDF.

In this research, 9 points along the central line with $0.5 \mathrm{~m}$ intervals were used to estimate the illuminance distribution on a working plane positioned at a height of $0.75 \mathrm{~m}$ above floor level. The room was assumed to be used as a private office for two people, with one positioned near the window and the second at the back of the room. As glare caused by daylight is less likely to be an issue at the back of the room, the glare evaluation was based on a viewpoint representing the occupant near the window. This was located at a distance of $1.2 \mathrm{~m}$ from the window and at a height of $1.2 \mathrm{~m}$ above the floor on the centre axis of the room.

Useful Daylight Illuminance (UDI) [46] is used as a metric when exploring the daylight availability of the office served by windows with integrated CdTe glazing. This metric adopts lower and upper thresholds to divide the illuminance level during the working hours of a year into three bins: an undersupply bin where illuminance value is below 100lux (UDI $<100$ lux), which suggests that the daylight illuminances are insufficient as a sole source of light; an oversupply bin where illuminance value is above 2000lux (UDI > 2000 lux), which indicates that the daylight illuminances are very likely to lead to visual and/or thermal discomfort; and a useful bin where illuminance value is in the range of 100 and 2000lux ( $\mathrm{UDI}_{100-2000}$ lux $)$, which is considered to provide useful levels of illuminance. The useful bin is further split into two ranges by 500 lux, which is the lower threshold that no artificial lighting is required [46]. In this study, UDI $500-2000 \mathrm{kx}$, was chosen as the most desirable illuminance range. This is the illuminance requirement for a typical office satisfied by only natural daylight which does not exceed the point where glare is highly likely [47]. In order to evaluate the daylight comfort level of the indoor space, Daylight Glare Probability (DGP), which was introduced and validated by Wienold and Christofferen [48], [49], [50], is selected for assessing discomfort glare. A simplified annual 
method of obtaining DGP, which is based on the vertical illuminance at the view point (see Fig. 2) during each time-step, provides hourly DGP values over a period of a year [48], [49]. Similar to UDI, thresholds of 0.35, 0.40 and 0.45 can be used to divide the DGP results calculated for occupied hours of a year into four bins: lower than 0.35 is 'imperceptible' glare sensation, between 0.35 and 0.40 is 'perceptible' between 0.40 and 0.45 is 'disturbing', while higher than 0.45 is deemed 'intolerable' [48]. 


\section{Result and discussion:}

\subsection{Energy performance after applying window integrated CdTe glazing}

This section presents the annual energy consumption of the office for the different window designs, with and without the integrated CdTe glazing. The energy consumption is expressed in terms of kWh per year and they are further divided into heating, cooling, lighting energy consumption and power generation by CdTe solar cells.

\subsubsection{Energy consumption for different PV covering rate under different WWR}

The first question in this study sought to determine the effect of applying window integrated CdTe glazing on the overall energy consumption with different WWRs under different climates. The predicted energy consumption, electrical power generation and the net energy consumption of the office can be found in Fig. 5. To have an overall understanding of the WWR and PV covering rate on building performance, for each PV covering rate, if there is more than one design scenario occurring, such as 50\% PV_1 and 50\% PV_2 under 30\% WWR, an average value is presented in Fig. 5. As can been seen, when the window-to-wall ratio is $30 \%$, fully applying CdTe glazing (100\% PV) leads to a higher energy consumption compared with normal double glazing under all climates tested. This is because there is a significant increase of lighting energy consumption due to the low visible transmittance of CdTe glazing, as well as an increased heating energy consumption due to less solar heat gain that is transmitted through the window for winter passive heating. Replacing $50 \%$ of the window area (50\% PV coverage rate) by CdTe glazing for $30 \%$ WWR results in a minimal to negligible difference of overall energy consumption when compared with ordinary double glazing. The $0.9 \%$ increase of the overall energy consumption for the Beijing scenario is the most prominent evidence of this. $2.2 \%, 1.6 \%, 7.0 \%$, and $8.2 \%$ reductions were found for Harbin, Shanghai, Guangzhou and Kunming, respectively. This is a consequence of the electrical power generated by the solar cells being offset by the increased lighting and heating energy consumptions. Thus, considering the investment of solar cells, it is not recommended to apply the selected STPV glazing to small window-to-wall ratios (i.e. WWR $=30 \%$ ).

With the increase of WWR from $45 \%$ to $75 \%$, the energy saving potential of using the selected CdTe glazing increases. Covering $67 \%, 75 \%$ and $80 \%$ of the window area by STPV glazing gave rise to the lowest overall energy consumption for $45 \%, 60 \%$ and $75 \%$ WWRs, respectively. This can be explained by the fact that, although the presence of CdTe glazing increases the heating and lighting load, it simultaneously reduces the cooling demands significantly. The balance between the generated electrical powers, reduced cooling loads and increased heating and lighting loads yields a significant energy conservation potential. The largest energy saving exists when coving $80 \%$ of the window area by STPV glazing for $75 \%$ WWR, as reductions in net energy consumption of $71.5 \%, 67.9 \%, 50.8 \%, 36.9 \%$ and $72.0 \%$ can be achieved for Harbin, Beijing, Shanghai, Guangzhou and Kunming, respectively.

As mentioned in previous sections, small WWR is regarded as the most energy efficient façade design strategy as it will limit the undesired heat loss and heat gain through the window element. However, larger 
window is more preferable for moderate architecture design. The results of this study give evidence that, if large WWR is the necessary choice from the architects' point of view, adoption of window integrated CdTe glazing at large WWR may deliver competitive energy efficient when compared with applying ordinary double glazing at small WWR. For example, in Beijing climates, the net energy consumption of applying ordinary double glazing at $30 \% \mathrm{WWR}$ is $1087.2 \mathrm{kWh} / \mathrm{year}$. Tested cases of: $33 \%$ and $67 \%$ window area coverage by CdTe glazing for $45 \%$ WWR; $50 \%$ and $75 \%$ window area coverage by CdTe glazing for $60 \%$ WWR; and $60-100 \%$ of window area coverage by CdTe glazing for $75 \%$ WWR, lead to less energy consumption. Thus, the adoption of window integration with the selected CdTe glazing is recommended for middle-size to extra-large window-to-wall ratios (i.e. WWR $\geq 45 \%$ ).

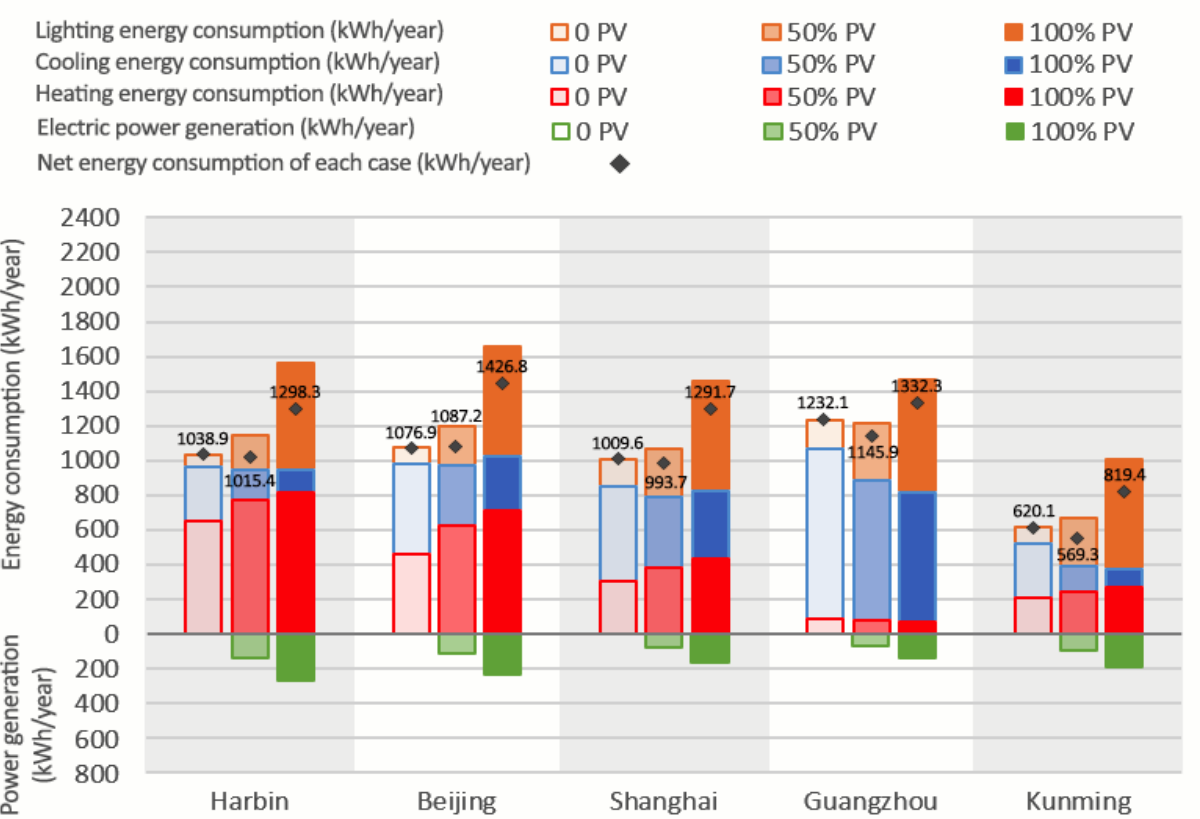

(a) $30 \% \mathrm{WWR}$

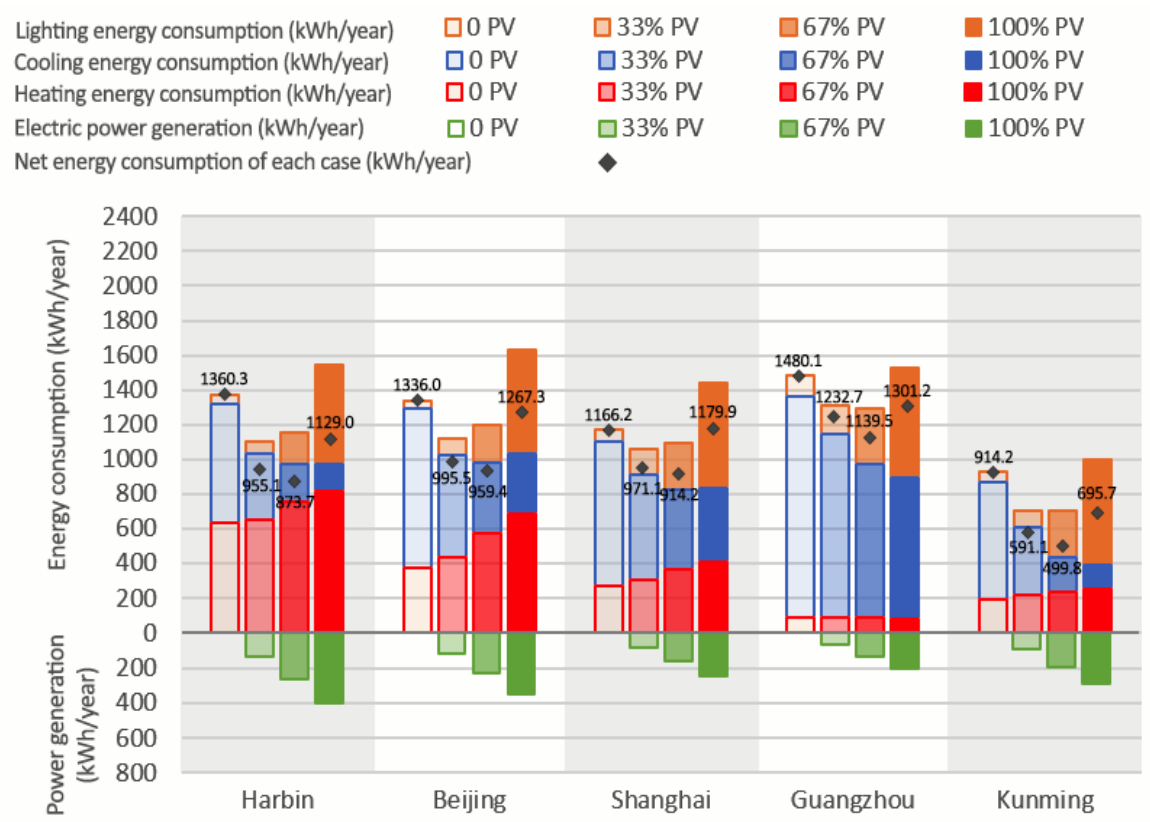

(b) $45 \% \mathrm{WWR}$ 

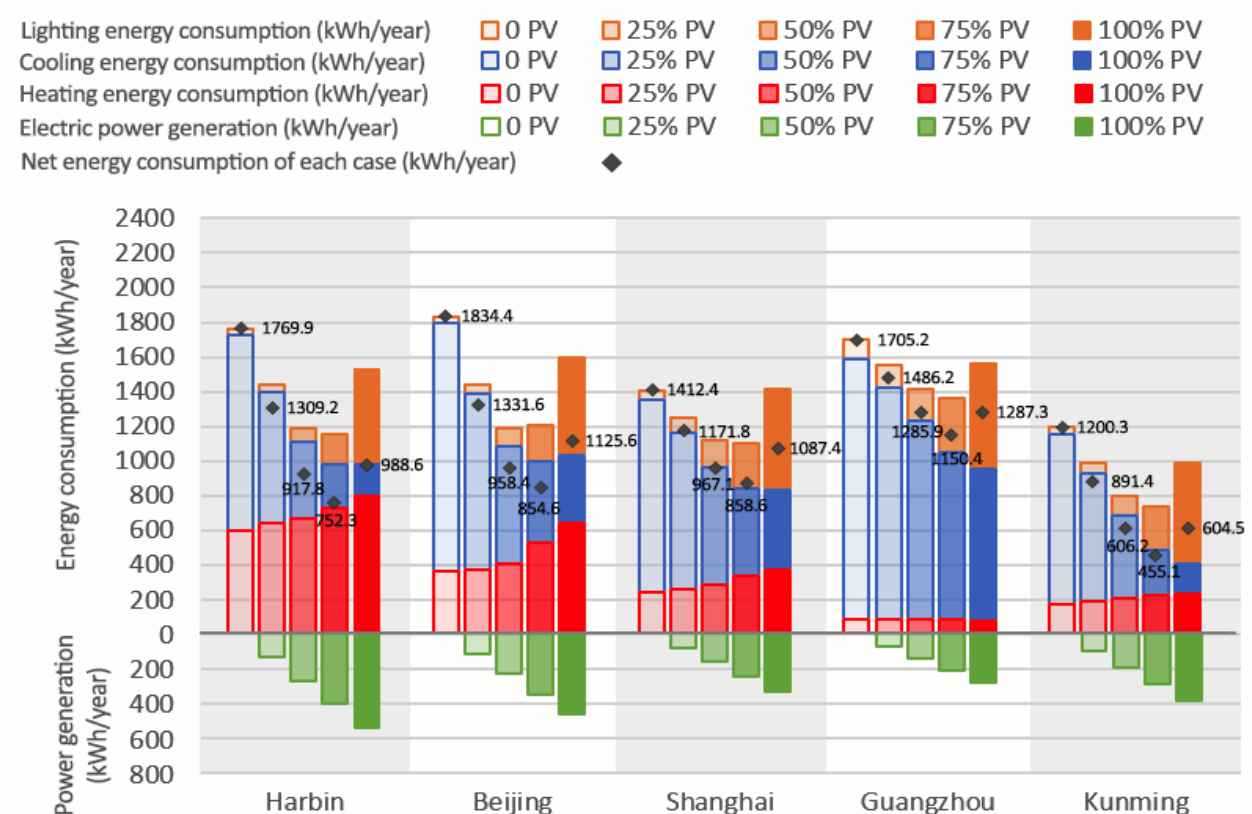

(c) $60 \% \mathrm{WWR}$

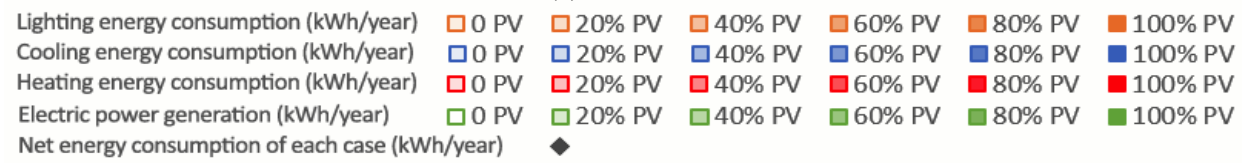
Net energy consumption of each case (kWh/year)

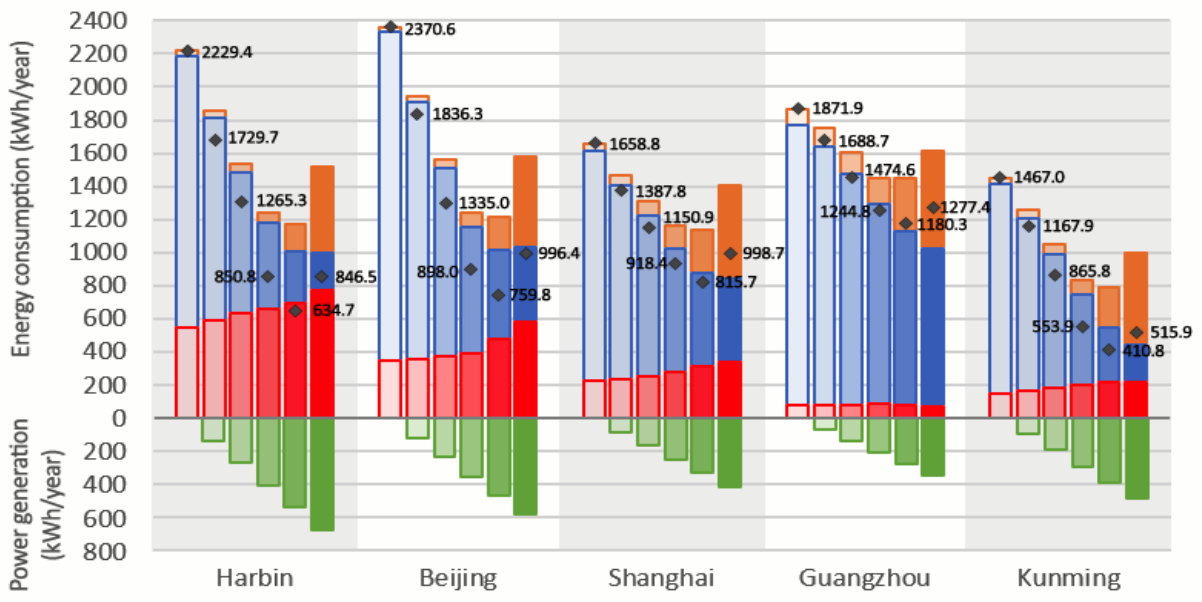

(d) $75 \%$ WWR

Fig. 5: Energy performance after applying window integrated CdTe glazing for (a) $30 \%$ WWR, (b) $45 \%$ WWR, (c) $60 \%$ WWR and (d) $75 \%$ WWR

\subsubsection{Energy consumption for different design}

To compare the performances of applying the same size of CdTe glazing but at different positions in a window, the energy consumptions and power generations of different designs are predicted in Fig. 6 . In the purpose of reducing work load, other than repeating simulations for 5 cities, only Harbin and Guangzhou have been selected in the following discussions, representing the coldest climate with a high latitude and the hottest climate with a low latitude, respectively. These figures that show the performance of different window design are grouped by the number of STPV glazing pane(s). For example, Fig. 6 (a) and (b) shows applying only 1 
PV glazing pane for 30\% WWR, 45\% WWR, 60\% WWR and 75\% WWR, while each WWR has 2 designs named as Design 1 and Design 2. In all cases shown in Fig. 6 (a) and (b), and in the case of 2 PV glazing panes for $75 \%$ WWR in Fig. 6 (c) and (d), the CdTe glazing placement within the windows doe not significantly affect the energy consumption under both climates. This suggests that when only covering a small proportion of the window area by CdTe glazing (i.e. area of CdTe glazing is significantly smaller than area of clear glazing) the CdTe glazing placement is overall an unimportant window design factor. On the opposite hand, when only a small proportion of a large window area is covered by clear glazing, as shown in case of 3 PV glazing panes for 60\%WWR in Fig. 6 (e) and (f) and case of 4 PV glazing panes for 75\%WWR in Fig. $6(\mathrm{~g})$ and $(\mathrm{h})$, the position of placing clear glazing has an influence on the overall energy consumption under both climates. Placing the clear glazing at an upper-middle level position yields the lowest net energy consumption. In Guangzhou, the differences of net energy consumption between the best and worst designs are approximate $20.0 \%$ and $30.8 \%$ for $3 \mathrm{PV}$ glazing panes of $60 \% \mathrm{WWR}$ and $4 \mathrm{PV}$ glazing panes of $75 \%$ WWR, respectively. Simultaneously, in Harbin, those are $25 \%$ and $45 \%$ for 3 PV glazing panes of $60 \%$ WWR and 4 PV glazing panes of $75 \%$ WWR, respectively. Lighting load is the dominant mechanism through which the difference between each design is evident. Another observation is that when the area of CdTe glazing is slightly larger or equal to the area of clear glazing, such as $2 \mathrm{PV}$ glazing panes of $60 \% \mathrm{WWR}$ in Fig. 6 (c) and (d) and 3 PV glazing panes of 75\%WWR in Fig. 6 (e) and (f), the position of placing clear glazing has a larger influence on the net energy consumption in Guangzhou than that in Harbin. For example, for 3 PV glazing panes of 75\%WWR, when compared with the least energy efficient design (Design 1), which has clear glazing placed on the bottom, the optimum design (Design 2) leads to $18.9 \%$ less energy consumption in Guangzhou while only $9 \%$ in Harbin. This is because, Guangzhou lies nearer the equator, which means the noon solar altitude is high. As a consequence, the sunlight with relatively high solar altitude is difficult to penetrate deeper into rooms. Thus, properly placing the clear glazing at upper-middle level locations will significantly amplify the natural daylight that passes through the window and hence reduce lighting energy load.

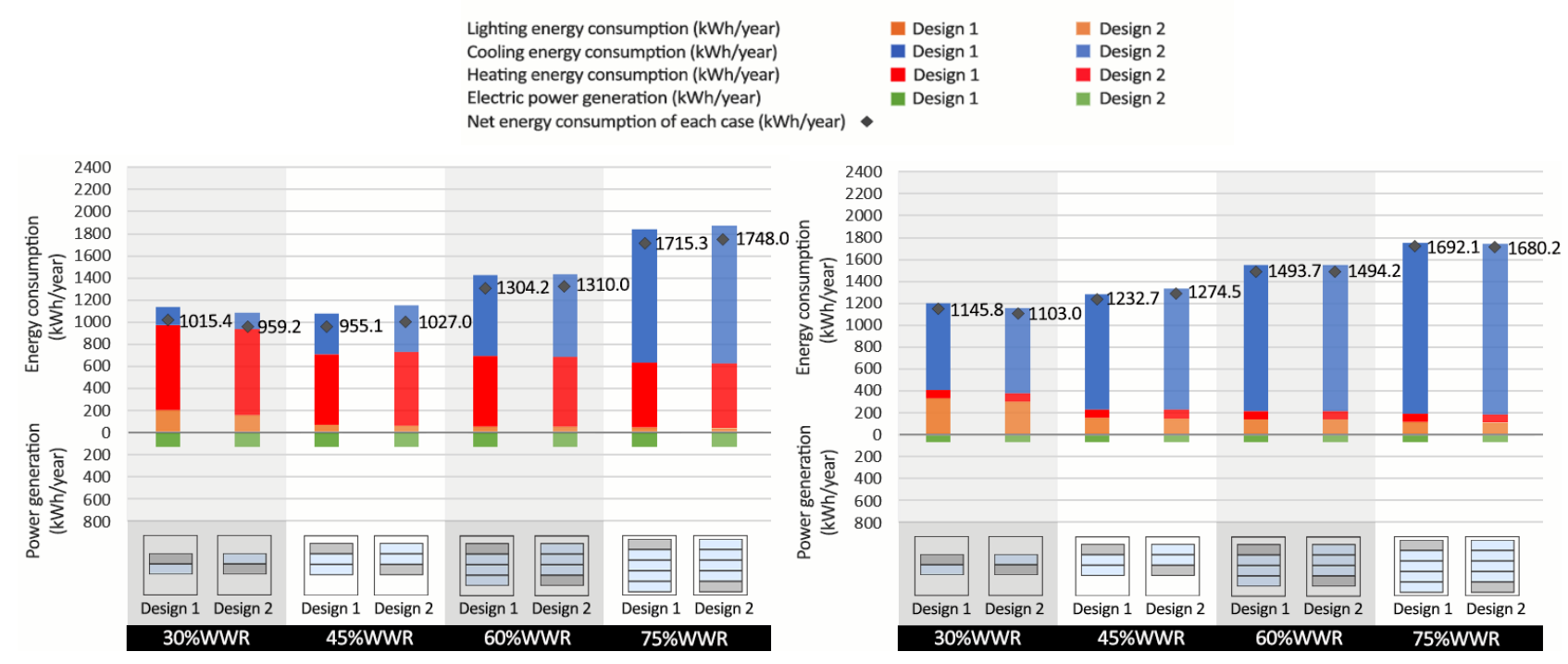

(a) adoption of $1 \mathrm{PV}$ glazing pane, for Harbin climate

(b) adoption of $1 \mathrm{PV}$ glazing pane, for Guangzhou cliamte 


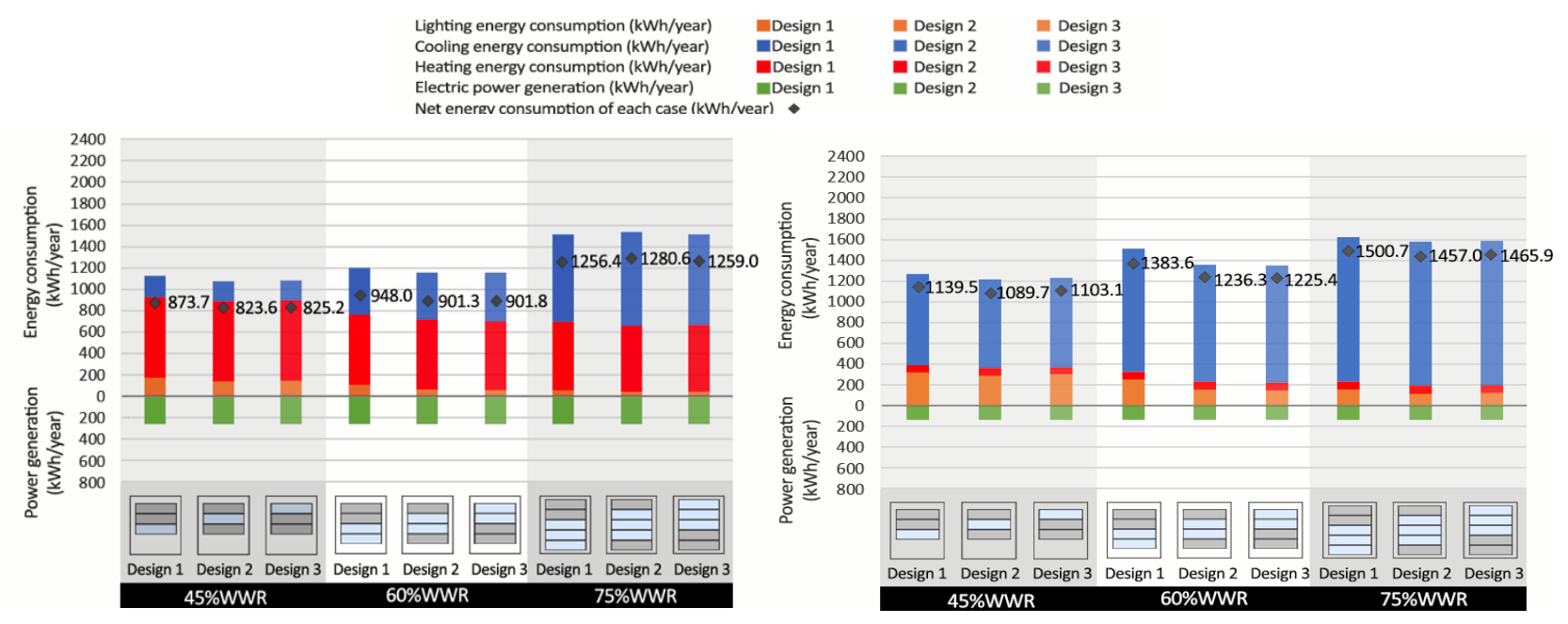

(c) adoption of 2 PV glazing panes, for Harbin climate

(d) adoption of $2 \mathrm{PV}$ glazing panes, for Guangzhou cliamte

\begin{tabular}{|c|c|c|c|c|}
\hline Lighting energy consumption ( $\mathrm{kWh} /$ year) & Design 1 & Design 2 & Design 3 & Design 4 \\
\hline Cooling energy consumption (kWh/year) & Design 1 & Design 2 & Design 3 & Design 4 \\
\hline Heating energy consumption ( $\mathrm{kWh} /$ year) & Design 1 & Design 2 & Design 3 & Design 4 \\
\hline Electric power generation (kWh/year) & Design 1 & = Design 2 & anesign 3 & Design 4 \\
\hline
\end{tabular}

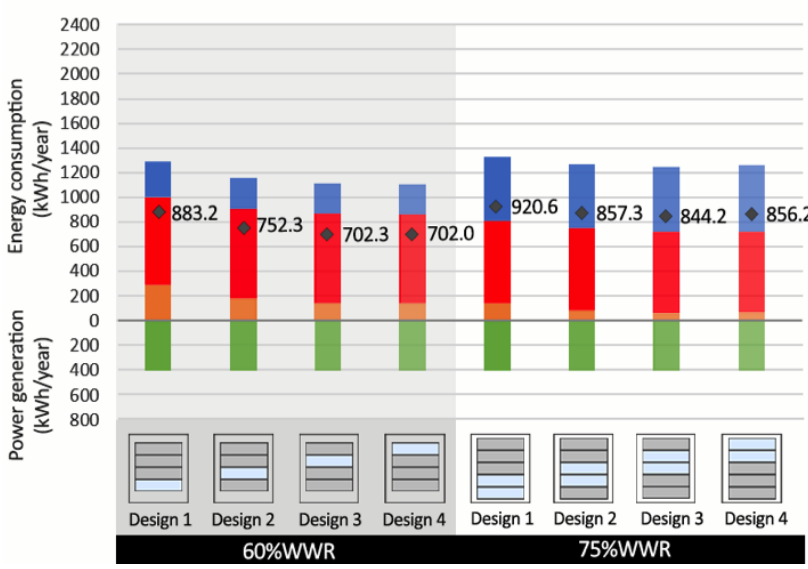

(e) adoption of 3 PV glazing panes, for Harbin climate

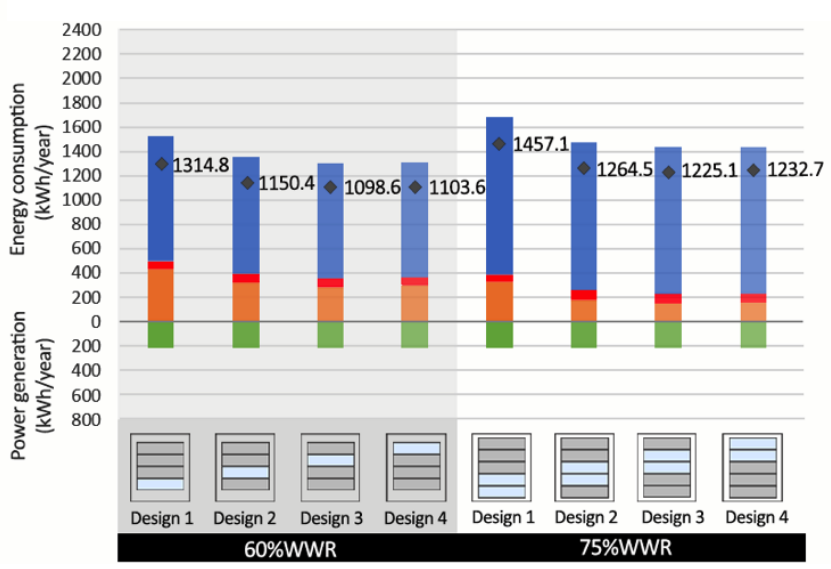

(f) adoption of $3 \mathrm{PV}$ glazing panes, for Guangzhou cliamte

Lighting energy consumption (kWh/year) mDesign 1 mesign 2 mDesign 3 mDesign 4 mDesign 5

Cooling energy consumption (kWh/year) Mesign 1 Design 2 mDesign 3 mDesign 4 mDesign 5

Heating energy consumption (kWh/year) Design 1 Design 2 Design 3 mDesign 4 mDesign 5

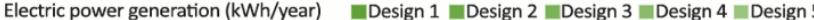

Net energy consumption of each case (kWh/year) •

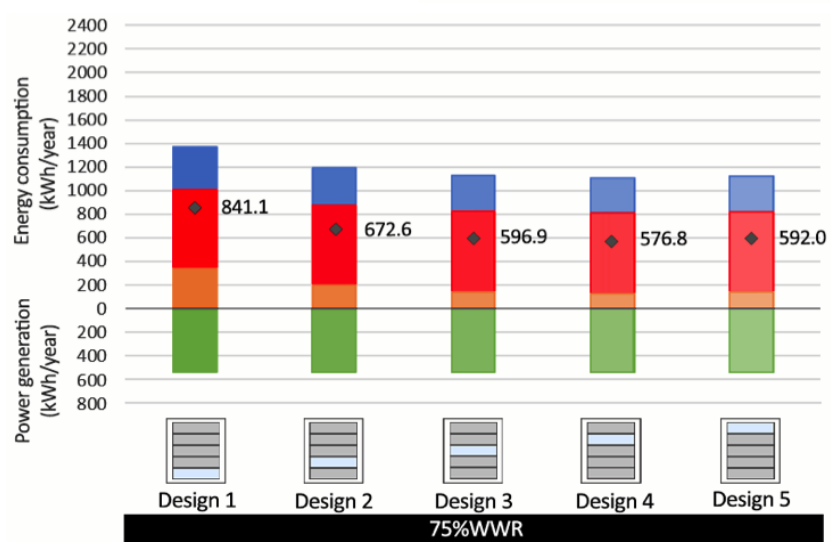

(g) adoption of 4 PV glazing panes, for Harbin climate

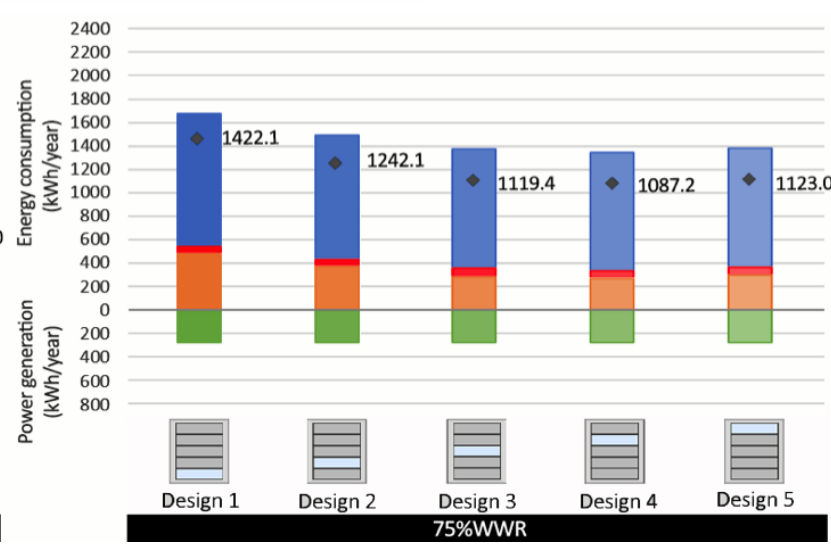

(h) adoption of 4 PV glazing panes, for Guangzhou cliamte 
Fig. 6: Energy consumption for different designs under (a) (c) (e) and (g) for Harbin's climate; (b) (d) (f) and (h) for Guangzhou's climate

\subsection{Daylight performance}

The analysis of daylight performances of adopting different window design scenarios of window integrated semi-transparent CdTe PV glazing was based on attaining a balance between daylight availability (represented by UDI) and daylight comfort level (represented by DGP).

\subsubsection{UDI for different PV covering rate under different WWR}

Fig. 7 (a)-(d) shows the distribution of data across the standard UDI bins used to quantify performance of window system with and without integrated semi-transparent CdTe PV glazing under different WWRs under the climate of Harbin. Fig. 7 (i)-(iv) shows data for the modified bin size (UDI ${ }_{500-2000 \text { lux }}$, which captures only data that meet the design illuminance of at least 500 lx. Similarly, Fig. 8 represents standard UDI bins and UDI ${ }_{500-2000 ~ l u x}$ for Guangzhou's climate. This provides greater detail than using the $\mathrm{UDI}_{100-2000}$ lux bin alone.

The ordinary double glazed system shows similar daylight performance for each WWR. In the region close to the window, a significant proportion of the working hours show over illumination (i.e. appearing in the $\left.\mathrm{UDI}_{>} 2000 \mathrm{bin}\right)$. As a consequence, only a small number of hours fall into the desirable levels of illumination

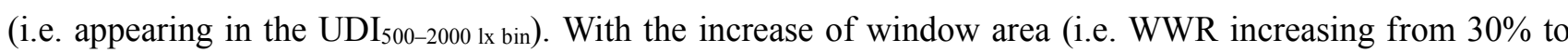
$75 \%$ ), over-illuminated conditions become more severe for the zone near to the window. For the same WWR, the over-illuminated conditions in Harbin are worse than that in Guangzhou. Partly covering the window area by STPV glazing can effectively improve the luminous environment in the entire room by reducing the hours of over illumination, while fully applying STPV glazing over the window area leads to under-illuminated conditions in the deeper area of the room. The optimum covering rate for each WWR in terms of daylight performance optimization is in accordance with that in terms of maximum energy efficiency. Taking ' $80 \%$ PV_WWR 75\%' under Guangzhou's climate as an example, in the near window half part of the office, the percentage of hours where the UDI is in the useful range (i.e. UDI $500-2000$ lux) increases from 13 32\% for the conventional DG and from 30 52\% for the window with integrated STPV glazing. For the rear area in the office; UDI ${ }_{100-2000}$ lux increases from $32 \sim 40 \%$ for the conventional DG and approximately $52 \sim 57 \%$ for the window with the integrated STPV glazing. 


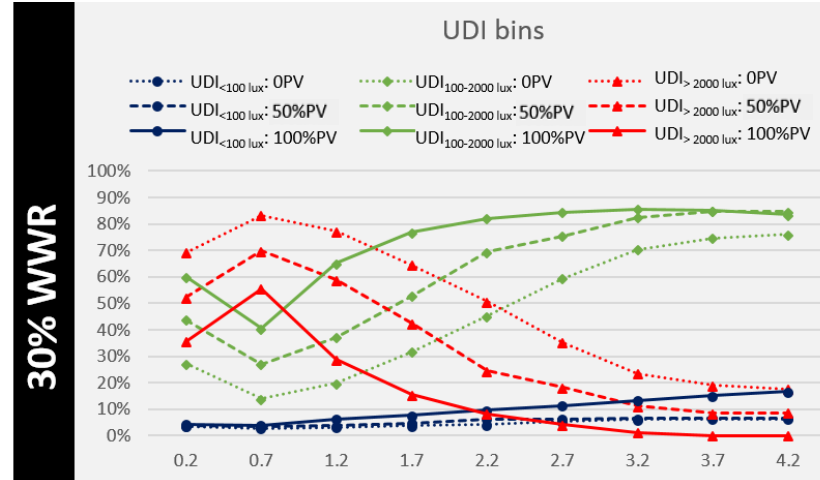

(a)

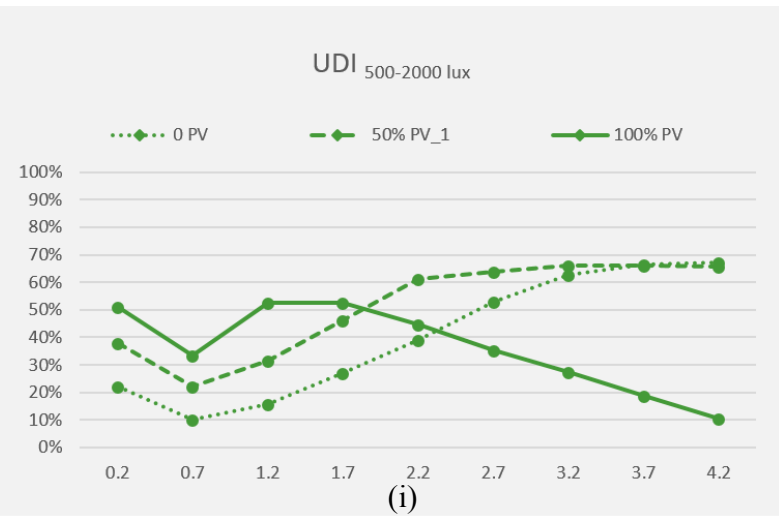

(i)

UDI bins

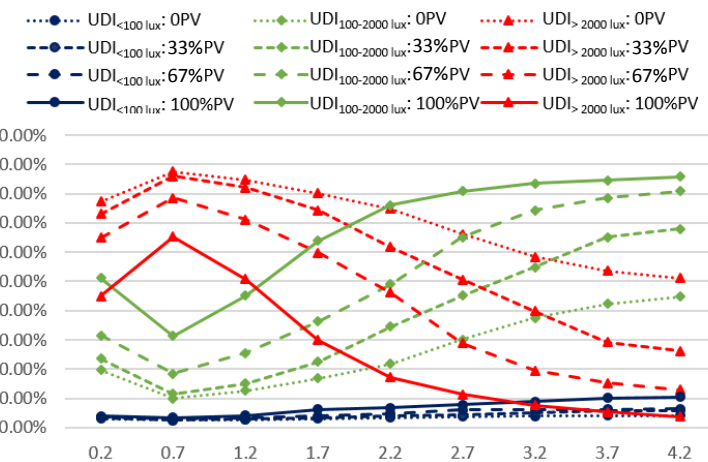

(b)

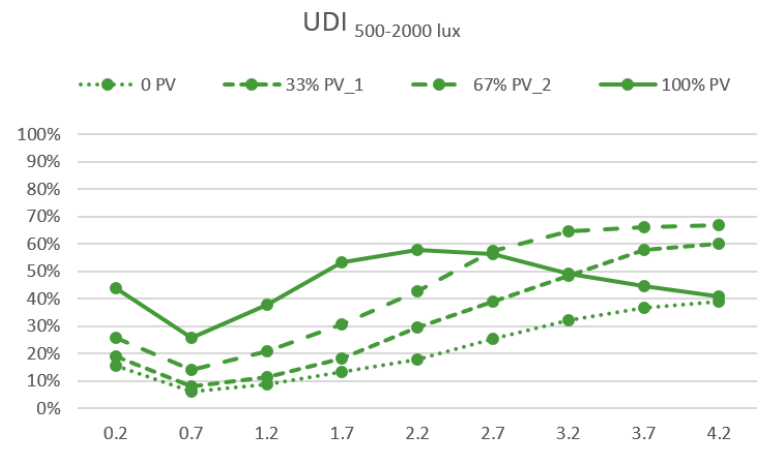

(ii)

UDI bins

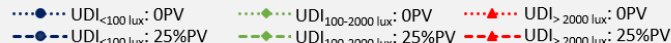

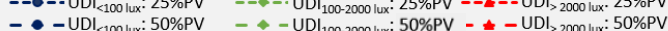

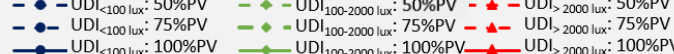

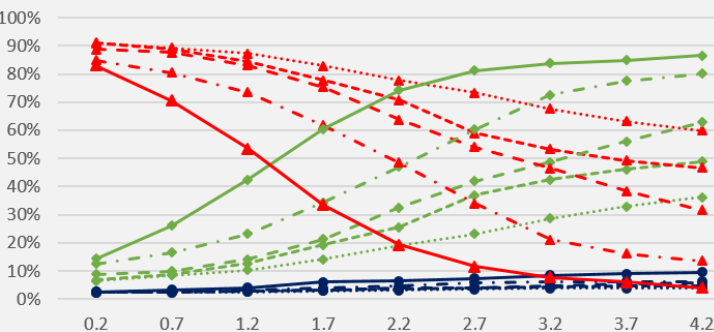

(c)

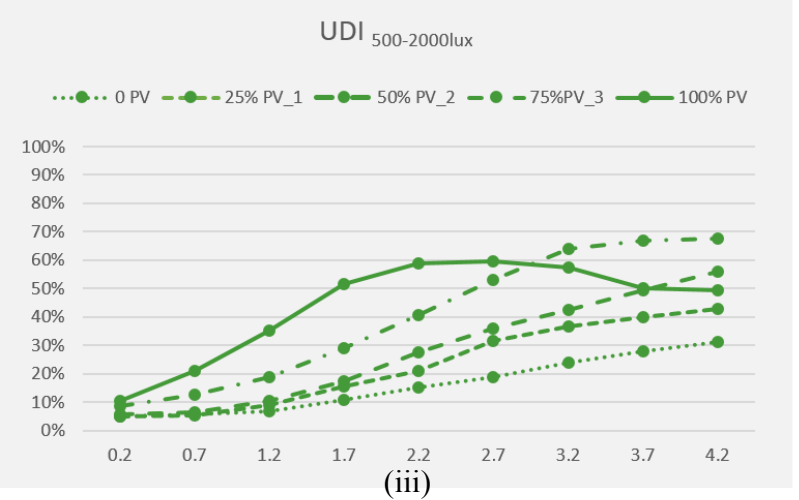

(iii)

UDI bins
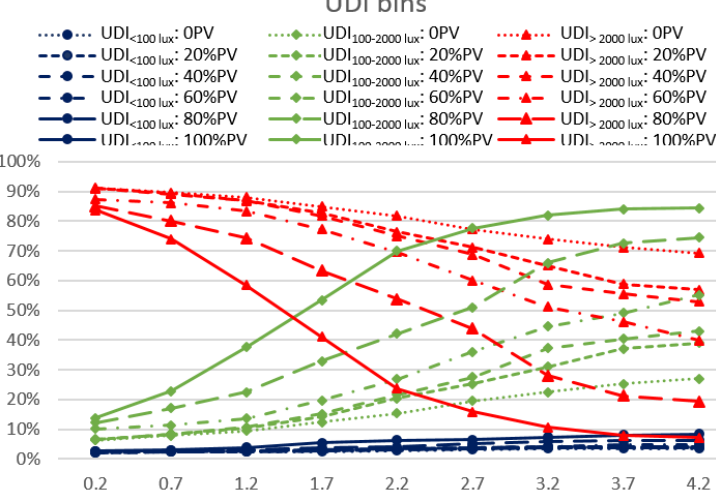

(d)
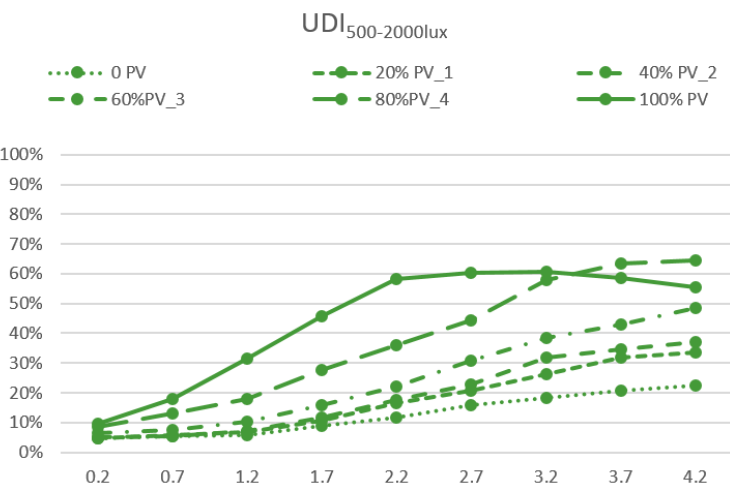

(iv)

Fig. 7. (a-d) standard three UDI bins and (i -iv) UDI 500-2000 lx bin at points along central line from south-facing window to end wall with different designs for window integrated CdTe glazing under Harbin's climate condition. 


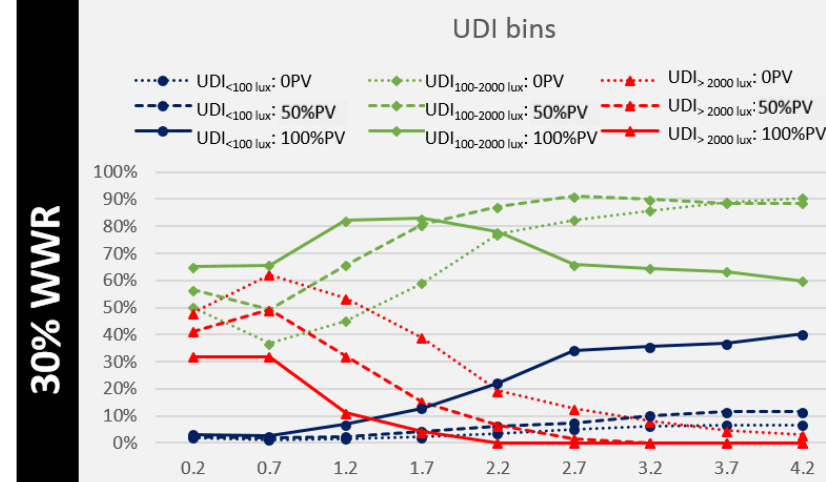

(a)

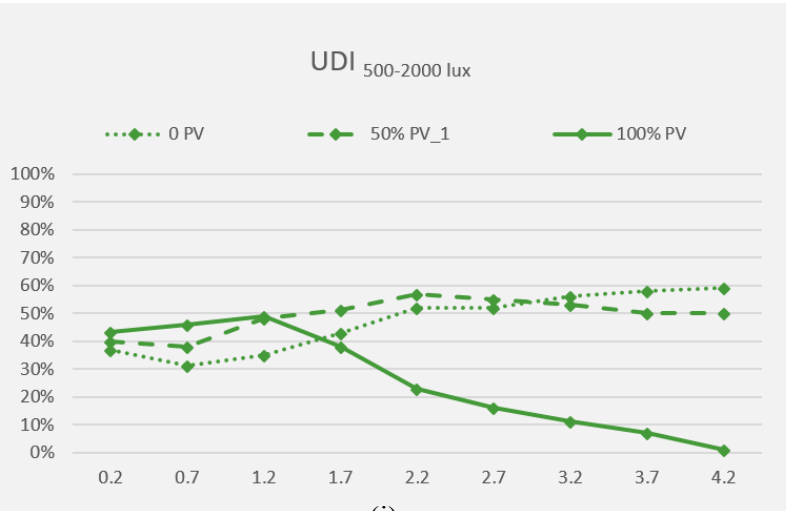

(i)

UDI ${ }_{500-2000 ~ l u x}$

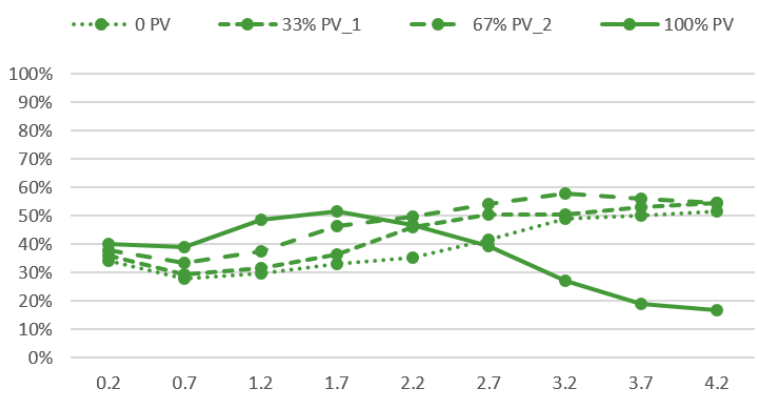

(ii)

(b)

UDI bins

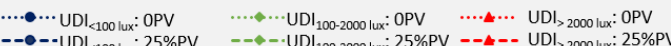

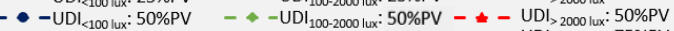

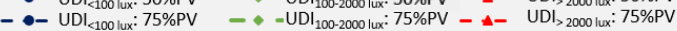

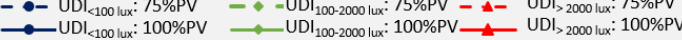

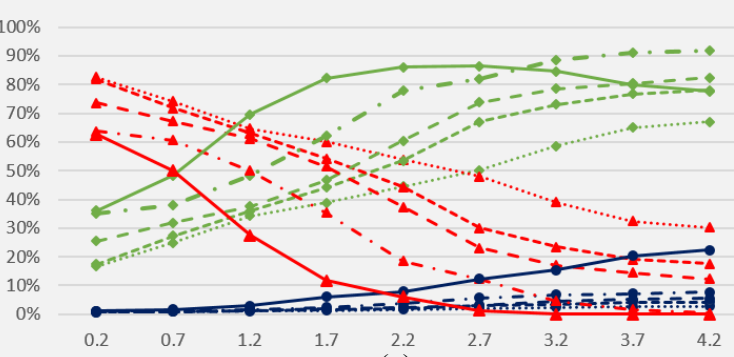

(c)

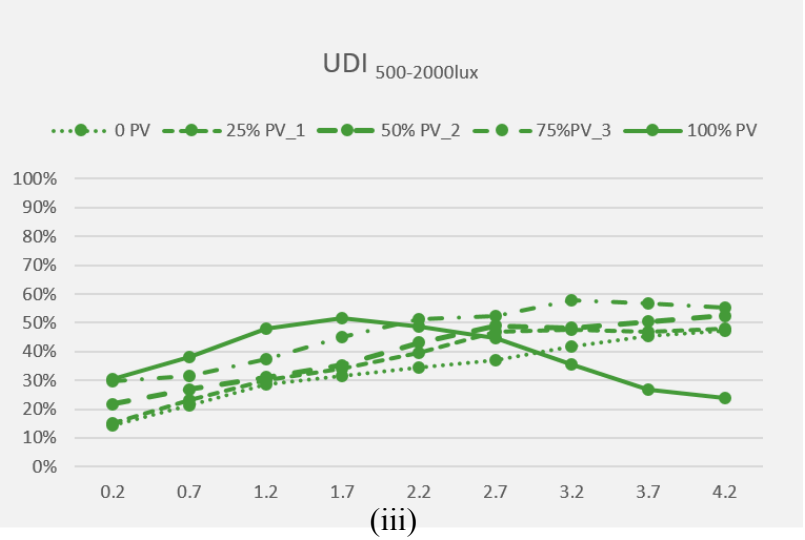

(iii)

UDI bins

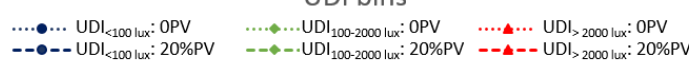

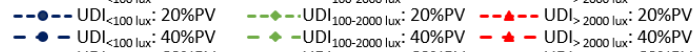

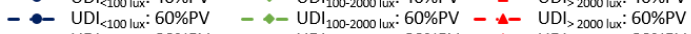

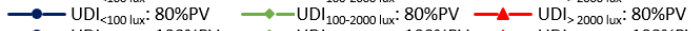

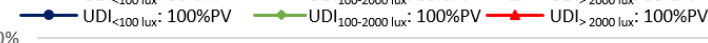
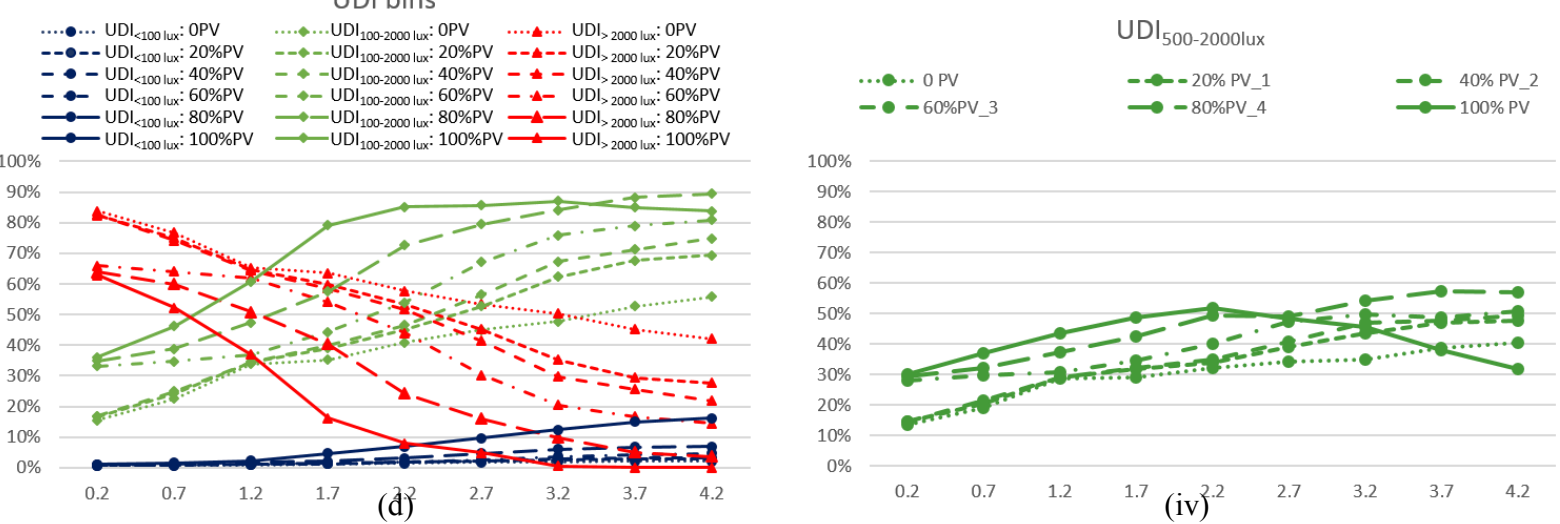

Fig. 8. (a-d) standard three UDI bins and (f-j) UDI 500-2000 lx bin at points along central line from south-facing window to end wall with different designs for window integrated CdTe glazing under Guangzhou's climate condition. 


\subsubsection{Glare Comfort}

When the luminance level within the view field exceeds the brightness that the human eyes can adapt to, glare caused by daylight occurs [41]. Daylight Glare Probability (DGP) technique was used to evaluate daylight glare within the office space and the annual predictions of the DGP for different window designs under Harbin and Guangzhou's climate at the view point (illustrated in Fig. 4) are shown in Fig. 9. Comparing all these scenarios in Harbin with those in Guangzhou, it can be seen that a low latitude (Guangzhou) result in more hours of imperceptible glare and thus a better glare ratings overall. This can be explained by the mid-day solar altitude being higher for lower latitudes which results in a reduction of direct solar radiation penetrating through the south-facing window system and thus impacting less on the occupant's in the room. For each climate, increasing the WWR increases the hours for intolerable glare.

According to the Wienold's criteria threshold relating to the effectiveness of the daylit environment [41]; the 'Best' classification is a scenario whereover 95\% of office hours have imperceptible glare (DGP $\leqslant$ 0.35). At no point did the double-glazed unit come close to meeting the 'Best' classification. When integrated STPV glazing windows were applied, significant improvements in the percentage of imperceptible glare (DGP $\leqslant 0.35$ ) was achieved. For example, for $30 \%$ WWR under Harbin's climate, the figure increases from $61 \%$ of working hours for DG to $79 \%$ and $96.5 \%$ with the application of $50 \% \mathrm{PV}$ and $100 \% \mathrm{PV}$, respectively. For Guangzhou's climate, $50 \%$ and $100 \%$ PV covering ratios under $30 \%$ WWR and $100 \%$ PV covering ratio under $45 \%$ WWR can meet the requirement of the 'Best' classification. The $100 \% \mathrm{PV}$ under $45 \% \mathrm{WWR}$ for Harbin, and $100 \% \mathrm{PV}$ for $60 \%$ WWR for Guangzhou offers a 'Good' classification as for over $95 \%$ of office working hours. The $100 \%$ PV for $75 \%$ WWR for Guangzhou have a 'Reasonable' classification as less than $5 \%$ of office working hours have intolerable glare.

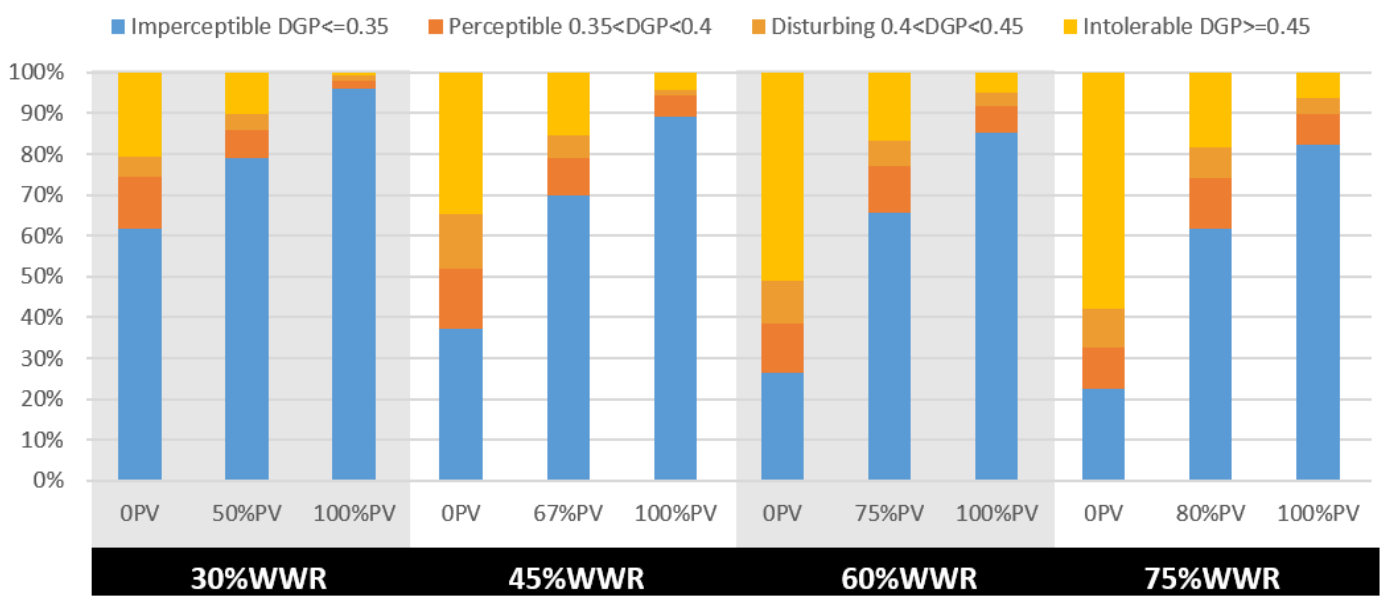

(a) 
च Imperceptible DGP $<=0.35 \quad$ Perceptible $0.35<\mathrm{DGP}<0.4 \quad$ Disturbing $0.4<\mathrm{DGP}<0.45 \quad$ - Intolerable DGP $>=0.45$

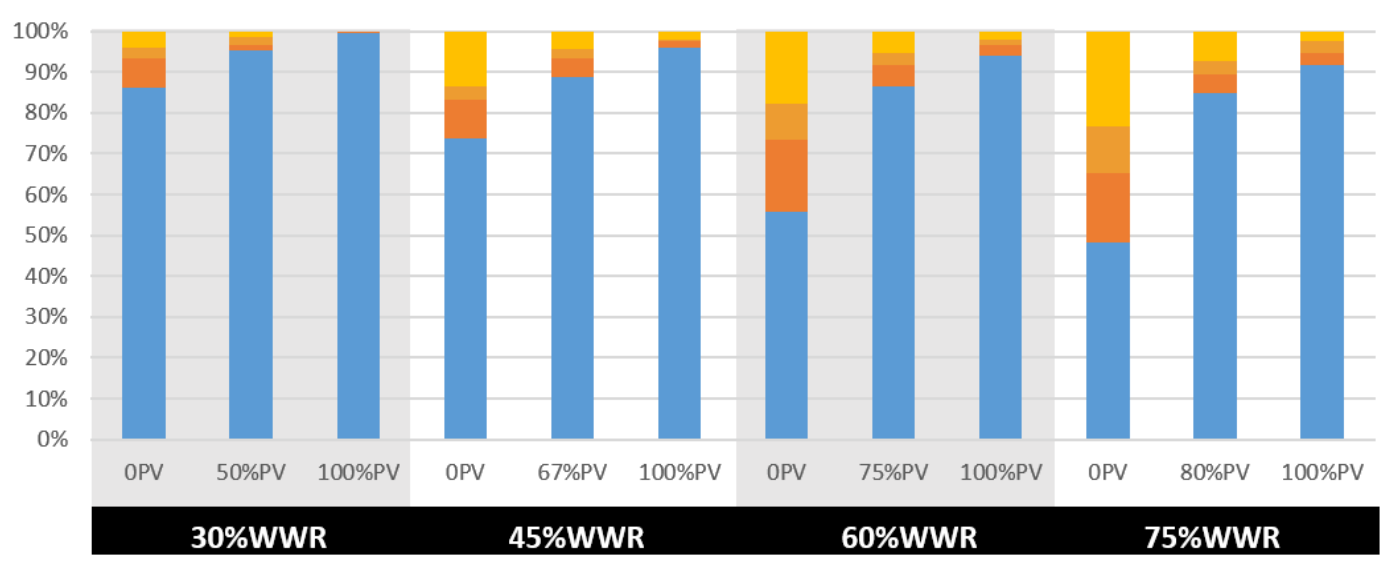

(b)

Fig. 9 Daylight Glare Probability (DGP) for the view point under different designs for window integrated CdTe glazing under (a) Harbin's climate and (b) Guangzhou's climate 


\section{Conclusions}

The design factors of window integrated semi-transparent photovoltaic (STPV) glazing were evaluated using an innovative approach (combined optical, electrical and energy model) for their effects on building energy performance and luminous environment quality when subjected to varying climate conditions. EnergyPlus has been used to predict the impact of semi-transparent CdTe glazing on building heating, lighting and cooling energy consumption. While, RADIANCE has been used as a complimentary approach to predict the detailed luminous environment of the spaces served by CdTe PV windows. The following conclusions can be drawn:

1) the adoption of the selected CdTe PV window can result in energy savings at large WWR while it is not recommended for using window integrated STPV glazing for WWR $\leqslant 30 \%$;

2) when WWR is larger than $45 \%$, window designs with a large portion of the area covered by STPV glazing while keeping sufficient daylighting area (clear glazing) (e.g. $80 \%$ of the window area is covered by STPV glazing when WWR is $75 \%$ ) give rise to the lowest net energy consumption under all those tested climates;

3) when applying STPV glazing to a large portion of window area, the energy efficiency of the system is higher under serve cold, cold and temperate climates (represented by Harbin, Beijing Kunming) while the lowest energy saving potential exists for hot climate (represented by Guangzhou);

4) for windows with integrated STPV glazing, if the area of clear glazing is significantly larger than that of STPV glazing, the position of placing STPV glazing has inadequate influence on the overall energy efficiency. Placing the clear glazing at a upper-middle level location would provide best energy efficiency if only a small proportion of the window is covered by clear glazing;

5) the most energy efficient design (designs with a large portion of the window area covered by STPV glazing while keeping sufficient daylighting area) also provides the optimum daylight availability under the climate of Guangzhou, while covering the whole window area by STPV glazing provides the optimum daylight availability under the climate of Harbin, especially for regions near the window; however, if considering the overall energy consumption, designs with large portion of STPV glazing and small portion of clear glazing can provide more advantages;

6) the undesired glare that caused by applying conventional double-glazing window can be essentially eliminated through applying window integrated STPV glazing.

In conclusion, the adoption of window integrated semi-tranparent CdTe PV glazing over conventional double-glazed windows offers a range of benefits for the carbon footprint of, and occupants' comfort within, the buildings. Our study provides a first step in developing design strategies that seek to balance implement of window integrated STPV glazing with the improvements in energy efficiency and luminous environment of spaces served by it. 
This study has restricted itself to exploring the performance of semi-transparent CdTe PV glazing with $10 \%$ transparency. The influence of the transparency of the STPV glazing on the energy consumption, power generation and indoor luminous environment will be presented in further research papers. The effects that semi-transparent CdTe PV glazing has on the view into and out of a building are also not considered in this study, and this represents a limitation that requires further study.

\section{Acknowledgements}

This work is jointly founded by the Innovate UK and China MoST Research Project E-IPBTS/P009263/1-102880 and 2016YFE0124500. The authors acknowledge all funding agencies for their support. 


\section{References}

1. Shukla, A.K., K. Sudhakar, and P. Baredar, Recent advancement in BIPV product technologies: A review. Energy and Buildings, 2017. 140: p. 188-195.

2. IPCC, SPECIAL REPORT ON RENEWABLE ENERGY. 2011.

3. Peng, J., et al., Developing a method and simulation model for evaluating the overall energy performance of a ventilated semi-transparent photovoltaic double-skin facade. Progress in Photovoltaics: Research and Applications, 2016. 24(6): p. 781-799.

4. Peng, J., et al., Comparative study of the thermal and power performances of a semi-transparent photovoltaic façade under different ventilation modes. Applied Energy, 2015. 138: p. 572-583.

5. Cuce, E., P.M. Cuce, and C.-H. Young, Energy saving potential of heat insulation solar glass: Key results from laboratory and in-situ testing. Energy, 2016. 97: p. 369-380.

6. Wang, D., et al., Band alignment of CdTe with MoO $x$ oxide and fabrication of high efficiency CdTe solar cells. Solar Energy, 2018. 162: p. 637-645.

7. Skandalos, N. and D. Karamanis, PV glazing technologies. Renewable and Sustainable Energy Reviews, 2015. 49: p. 306-322.

8. Yang, T. and A.K. Athienitis, A review of research and developments of building-integrated photovoltaic/thermal (BIPV/T) systems. Renewable and Sustainable Energy Reviews, 2016. 66: p. 886912.

9. Wang, M., et al., Assessment of energy performance of semi-transparent PV insulating glass units using a validated simulation model. Energy, 2016. 112: p. 538-548.

10. Skandalos, N. and D. Karamanis, Investigation of thermal performance of semi-transparent PV technologies. Energy and Buildings, 2016. 124: p. 19-34.

11. Peng, J., L. Lu, and H. Yang, An experimental study of the thermal performance of a novel photovoltaic double-skin facade in Hong Kong. Solar Energy, 2013. 97: p. 293-304.

12. Wang, M., et al., Comparison of energy performance between PV double skin facades and PV insulating glass units. Applied Energy, 2017. 194: p. 148-160.

13. Liao, W. and S. Xu, Energy performance comparison among see-through amorphous-silicon PV (photovoltaic) glazings and traditional glazings under different architectural conditions in China. Energy, 2015. 83: p. 267-275.

14. Myong, S.Y. and S.W. Jeon, Efficient outdoor performance of esthetic bifacial a-Si:H semi-transparent PV modules. Applied Energy, 2016. 164: p. 312-320.

15. Yamaguchi, T., et al., Highly efficient plastic-substrate dye-sensitized solar cells with validated conversion efficiency of 7.6\%. Solar Energy Materials and Solar Cells, 2010. 94(5): p. 812-816.

16. Polysolar, Building Integrated Transparent Photovoltaic Glass, http://www.polysolar.co.uk/, [accessed September 2018]

17. Yan, F., et al., Semitransparent OPV modules pass environmental chamber test requirements. Solar Energy Materials and Solar Cells, 2013. 114: p. 214-218.

18. Lee, H.M. and J.H. Yoon, Power performance analysis of a transparent DSSC BIPV window based on 2 year measurement data in a full-scale mock-up. Applied Energy, 2018. 225: p. 1013-1021.

19. Ghosh, A. Sundaram, S. Mallick, T. K. Colour properties and glazing factors evaluation of multicrystalline based semi-transparent Photovoltaic-vacuum glazing for BIPV application. Renewable Energy, 2019. 131: p. 730-736.

20. Ghosh, A. Sundaram, S. Mallick, T. K. Investigation of thermal and electrical performances of a combined semi-transparent PV-vacuum glazing. Applied Energy, 2018. 228: p.1591-1600.

21. Sabry, M. Abdel-Hadi, Y. A. Ghitas, A., PV-integrated CPC for transparent façades. Energy and Buildings, 2013. 66: p. 480-484.

22. Miyazaki, T., A. Akisawa, and T. Kashiwagi, Energy savings of office buildings by the use of semitransparent solar cells for windows. Renewable Energy, 2005. 30(3): p. 281-304.

23. Peng, J., et al., Validation of the Sandia model with indoor and outdoor measurements for semitransparent amorphous silicon PV modules. Renewable Energy, 2015. 80: p. 316-323. 
24. Zhang, W., et al., Comparison of the overall energy performance of semi-transparent photovoltaic windows and common energy-efficient windows in Hong Kong. Energy and Buildings, 2016. 128: p. 511-518.

25. Chow, T.T., et al., Performance evaluation of a PV ventilated window applying to office building of Hong Kong. Energy and Buildings, 2007. 39(6): p. 643-650.

26. Olivieri, L., et al., Energy saving potential of semi-transparent photovoltaic elements for building integration. Energy, 2014. 76: p. 572-583.

27. Olivieri, L. Caamaño-Martin, E. Olivieri, F. Neila. J., Integral energy performance characterization of semi-transparent photovoltaic elements for building integration under real operation conditions. Energy and Buildings, 2014. 68: p. 280-291

28. Kapsis, K. and A.K. Athienitis, A study of the potential benefits of semi-transparent photovoltaics in commercial buildings. Solar Energy, 2015. 115: p. 120-132.

29. Ma, P., L.-S. Wang, and N. Guo, Maximum window-to-wall ratio of a thermally autonomous building as a function of envelope $U$-value and ambient temperature amplitude. Applied Energy, 2015. 146: $p$. 84-91.

30. Acosta, I., M.Á. Campano, and J.F. Molina, Window design in architecture: Analysis of energy savings for lighting and visual comfort in residential spaces. Applied Energy, 2016. 168: p. 493-506.

31. Susorova, l., et al., The effect of geometry factors on fenestration energy performance and energy savings in office buildings. Energy and Buildings, 2013. 57: p. 6-13.

32. Goia, F., Search for the optimal window-to-wall ratio in office buildings in different European climates and the implications on total energy saving potential. Solar Energy, 2016. 132: p. 467-492.

33. Goia, F., M. Haase, and M. Perino, Optimizing the configuration of a façade module for office buildings by means of integrated thermal and lighting simulations in a total energy perspective. Applied Energy, 2013. 108: p. 515-527.

34. Bueno, B., et al., A systematic workflow for retrofitting office façades with large window-to-wall ratios based on automatic control and building simulations. Building and Environment, 2018. 132: p. 104-113.

35. Zhao, M. and Kunzel, H.M. and Antretter, F., Parameters influencing the energy performance of residential buildings in different Chinese climate zones. Energy and Buildings, 2015. 96(1): p. 63-75.

36. SOLARGIS, https://solargis.com/, [accessed September 2018]

37. Yanyi Sun, Y.W., Robin Wilson, A Review of Thermal and Optical Characterisation of Complex Window Systems and Their Building Performance Prediction. Applied Energy 2018. 222C: p. 729-747.

38. Sun, Y., et al., Development of a comprehensive method to analyse glazing systems with Parallel Slat Transparent Insulation material (PS-TIM). Applied Energy, 2017. 205: p. 951-963.

39. G. Ward and R. Shakespeare, Rendering with Radiance: The Art and Science of Lighting Visualization, Revised Edition. 2004: BookSurge, LLC.

40. M. Saxena, et al., Dynamic RADIANCE - Predicting annual daylight with variable fenestratio optics using BSDFs, in Fourth National Conference of IBPSA-USA. 2010: New York City, USA.

41. Reinhart, C. and S. Herkel, The simulation of annual daylight illuminance distributions - a state-ofthe-art comparison of six RADIANCE-based methods. Energy and Buildings, 2000. 32(2): p. 167-187.

42. Reinhart, C. and O. Walkenhorst, Validation of dynamic RADIANCE-based daylight simulations for a test office with external blinds. Energy and Buildings, 2001. 33(7): p. 683-697.

43. Reinhart, C. and M. Andersen, Development and validation of a Radiance model for a translucent panel. Energy and Buildings, 2006. 38(7): p. 890-904.

44. Ward, G., et al., Simulating the daylight performance of Complex Fenestration Systems using Bidirectional Scattering Distribution Functions within Radiance. Journal of the Illuminating Engineering Society of North America 2011. 7(4).

45. Sun, Y., Y. Wu, and R. Wilson, Analysis of the daylight performance of a glazing system with Parallel Slat Transparent Insulation Material (PS-TIM). Energy and Buildings, 2017. 139: p. 616-633.

46. Nabil, A. and J. Mardaljevic, Useful daylight illuminances: A replacement for daylight factors. Energy and Buildings, 2006. 38(7): p. 905-913. 
47. CF. Reinhart, Daylight performance predictions, in Building performance simulation for design and operation Jan L.M. Hensen and R. Lamberts, Editors. 2011, Spon Press: London.

48. Wienold, J., Dynamic daylight glare evaluation., in Builing simulation 2009 the 11th international IBOSA conference. 2009: Glasgow, UK. p. 44-51.

49. Wienold, J., Dynamic simulation of blind control strategies for visual comfort and energy balance analysis. , in Building simulation 2007, the 10th international IBOSA conference. 2007: Beijing, China. p. 1197-204.

50. Wienold, J. and J. Christoffersen, Evaluation methods and development of a new glare prediction model for daylight environments with the use of CCD cameras. Energy and Buildings, 2006. 38(7): $p$. 743-757. 